\title{
Modulation of hippocampal theta oscillations and spatial memory by relaxin-3 neurons of the nucleus incertus
}

\author{
Sherie Ma, ${ }^{1,2}$ Francisco E. Olucha-Bordonau, ${ }^{3}$ M. Akhter Hossain, ${ }^{1}$ Feng Lin, ${ }^{1}$ \\ Chester Kuei, ${ }^{4}$ Changlu Liu, ${ }^{4}$ John D. Wade, ${ }^{1,5}$ Steven W. Sutton, ${ }^{4}$ Angel Nuñez, ${ }^{6}$ \\ and Andrew L. Gundlach ${ }^{1,7,8}$ \\ ${ }^{1}$ Howard Florey Institute, The University of Melbourne, Victoria 3010, Australia; ${ }^{2}$ Department of Medicine, The University of \\ Melbourne, Austin Health, Heidelberg, Victoria 3084, Australia; ${ }^{3}$ Departamento de Anatomía y Embriología Humana, Facultad de \\ Medicina, Universidad de Valencia, 46010 Valencia, Spain; ${ }^{4}$ Neuroscience Drug Discovery, Johnson \& Johnson Pharmaceutical \\ Research \& Development, LLC, San Diego, California 92121, USA; ${ }^{5}$ Department of Chemistry, The University of Melbourne, \\ Victoria 3010, Australia; ${ }^{6}$ Departamento de Anatomia, Histología y Neurociencia Facultad de Medicina, Universidad Autónoma de \\ Madrid, 28029 Madrid, Spain; ' Department of Anatomy and Cell Biology, The University of Melbourne, Victoria 3010, Australia
}

\begin{abstract}
Hippocampal theta rhythm is thought to underlie learning and memory, and it is well established that "pacemaker" neurons in medial septum (MS) modulate theta activity. Recent studies in the rat demonstrated that brainstem-generated theta rhythm occurs through a multisynaptic pathway via the nucleus incertus $(\mathrm{NI})$, which is the primary source of the neuropeptide relaxin-3 (RLN3). Therefore, this study examined the possible contribution of RLN3 to MS activity, and associated hippocampal theta activity and spatial memory. In anesthetized and conscious rats, we identified the ability of intraseptal RLN3 signaling to modulate neuronal activity in the MS and hippocampus and promote hippocampal theta rhythm. Behavioral studies in a spontaneous alternation task indicated that endogenous RLN3 signaling within MS promoted spatial memory and exploratory activity significantly increased c-Fos immunoreactivity in RLN3-producing NI neurons. Anatomical studies demonstrated axons/terminals from NI/RLN3 neurons make close contact with septal GABAergic (and cholinergic) neurons, including those that project to the hippocampus. In summary, RLN3 neurons of the NI can modulate spatial memory and underlying hippocampal theta activity through axonal projections to pacemaker neurons of the MS. NI/RLN3 neurons are highly responsive to stress and express corticotropin-releasing factor type-1 receptors, suggesting that the effects observed could be an important component of memory processing associated with stress responses.
\end{abstract}

[Supplemental material is available online at http:// www.learnmem.org.]

Hippocampal theta oscillations of $4-12 \mathrm{~Hz}$ have been implicated in several neural functions and behaviors, including memory consolidation, arousal states such as exploratory behavior and rapid eye movement sleep, and the control of anxiety and mood (Vertes 1984, 2005; Klimesch 1999; McNaughton and Gray 2000). Growing evidence also suggests that theta rhythm may underlie long-term potentiation in the hippocampus and associated mnemonic processes (Vertes and Kocsis 1997; Vertes 2005). It is well established that activity of "pacemaker" GABAergic and cholinergic neurons in the medial septum (MS) is capable of generating and pacing hippocampal theta rhythm (Vertes and Kocsis 1997; Wang 2002; Simon et al. 2006). The supramammillary (SuM) and median raphe (MR) nuclei also have important roles in modulating hippocampal theta rhythm (Vertes and Kocsis 1997; Kirk and Mackay 2003; Kocsis 2006).

Recently, we have demonstrated that the pontine nucleus incertus (NI) functions in the generation of hippocampal theta rhythm. In urethane-anesthetized rats, electrical stimulation of the NI induced theta rhythm recorded in the hippocampus, while

${ }^{8}$ Corresponding author.

E-mail andrew.gundlach@florey.edu.au; fax 61-3-9348-1707. Article is online at http://www.learnmem.org/cgi/doi/10.1101//m.1438109. an excitotoxic lesion of the NI or local muscimol injection disrupted theta induction by stimulation of the main endogenous pontine initiator of theta rhythm, the reticularis pontis oralis (RPO) (Nuñez et al. 2006). The NI is a distinct cell group of the pontine periventricular gray, caudal to the dorsal raphe and adjacent to the fourth ventricle on the ventromedial border of the dorsal tegmental nucleus. It has widespread projections throughout the brain, including regions such as the MS, SuM, $\mathrm{MR}$, and the hippocampus and receives afferent projections from the medial prefrontal cortex, hippocampus, amygdala, lateral habenula, nucleus reuniens, superior colliculus, periaqueductal gray, interpeduncular nuclei, and RPO (Goto et al. 2001; OluchaBordonau et al. 2003; Teruel-Marti et al. 2008). Because the RPO and other brainstem structures do not have direct projections to the MS and other subcortical "pacemaker" regions (Vertes and Martin 1988), it has been postulated that the NI may act as a relay station in a multisynaptic pathway between the brainstem and theta pacemaker regions, such as the MS, SuM, and MR (OluchaBordonau et al. 2003; Teruel-Marti et al. 2008). The connectivity of the NI also suggests that it is positioned to modulate hippocampal theta activity in response to somatosensory prefrontal cortical information and lateral habenular processing of limbic and basal ganglia information (Goto et al. 2001; Olucha-Bordonau 
et al. 2003). In summary, the NI is in a strategic position to integrate information relating to behavioral planning and, in turn, is capable of modulating the activity of various limbic structures involved in the control of hippocampal theta activity, to elicit changes in learning and memory, arousal, and attentional state.

NI neurons are also the primary central source of the neuropeptide relaxin-3 (RLN3) in mouse (Bathgate et al. 2002), rat (Burazin et al. 2002; Tanaka et al. 2005; Ma et al. 2007), and macaque (Ma et al. 2009). Similarly, the distribution of RLN3-like immunoreactivity (-LI) in nerve fibers and terminations (Tanaka et al. 2005; Ma et al. 2007) corresponds well with that of anterograde tract-tracing from the NI (Goto et al. 2001; OluchaBordonau et al. 2003). RLN3 is a member of the relaxin and insulin-like peptide superfamily (Bathgate et al. 2002, 2006; Ma and Gundlach 2007), and although it is the most recently discovered member, phylogenic analysis has revealed that RLN3 is, in fact, the ancestral peptide, with a sequence highly conserved throughout evolution (Hsu 2003; Hsu et al. 2005; Wilkinson et al. 2005). Ultrastructural examination of RLN3-LI revealed that RLN3 is localized in dense-cored vesicles of neuronal perikarya and synaptic terminals (Tanaka et al. 2005), which suggests that RLN3 is synthesized in the NI and undergoes axonal transport in a "neuropeptide-like" manner. RLN3 neurons of the NI are GABAergic (Ma et al. 2007), and most coexpress corticotropinreleasing factor (CRF) receptor-1 (Tanaka et al. 2005). It has been postulated that owing to its proximity to the ventricle, the NI may exert some of the extra-pituitary actions of circulating CRF on autonomic and behavioral components of the stress response (Bittencourt and Sawchenko 2000; Goto et al. 2001). In fact, intracerebroventricular infusion of CRF has been shown to elicit neuronal activation of NI/RLN3 neurons in rats (Bittencourt and Sawchenko 2000; Tanaka et al. 2005). Moreover, expression of RLN3 mRNA (and heteronuclear mRNA) is enhanced following restraint stress (Tanaka et al. 2005), forced swim stress (Banerjee et al. 2006, 2009), and fluctuates across the light-dark cycle in rats (Banerjee et al. 2006), suggesting that the NI (and RLN3) is regulated by, and/or regulates, general arousal and attentional processes.

Extensive pharmacological studies suggest that the cognate receptor for RLN3 is relaxin family peptide receptor-3 (RXFP3), also known as GPCR135 (Liu et al. 2003; Sutton et al. 2004) or somatostatin- and angiotensin-like peptide receptor (SALPR) (Matsumoto et al. 2000). The distribution of RXFP3 mRNA and specific binding sites correlates with that of RLN3-LI in rat brain (Sutton et al. 2004; Ma et al. 2007). In an effort to investigate functional roles of this system, an RXFP3-selective chimeric agonist peptide, R3/I5, was generated by the combination of the RLN3 B-chain and insulin-like peptide-5 (INSL5) A-chain (Liu et al. 2005). Further truncation of the $C$ terminus of R3/I5 produced a specific antagonist peptide, R3(B $\Delta 23-27) \mathrm{R} / \mathrm{I} 5$ (Kuei et al. 2007). Intracerebroventricular infusion of R3/I5 produced a pronounced orexigenic effect, which was blocked by R3(B $\Delta 23-27) R / I 5$ (Kuei et al. 2007), findings in line with increased food intake observed after acute and chronic infusion of human RLN3 in rats (Hida et al. 2006; McGowan et al. 2006).

In light of the involvement of the NI in hippocampal theta generation (Nuñez et al. 2006), the aim of the present study was to elucidate the contribution of RLN3 signaling to this effect and related behavior. These studies focused on actions within the MS where RLN3-LI axons and terminations and RXFP3 are highly abundant (Ma et al. 2007). Hippocampal theta activity was measured from hippocampal electroencephalogram (EEG) recordings in anesthetized and unanesthetized rats following infusions of R3/I5 and/or R3(B $\Delta 23-27) R / I 5$ into the MS. Evoked fieldpotential recordings in the MS and hippocampus were also analyzed following electrical stimulation of the fimbria.
A role of RLN3 in a hippocampal theta rhythm-dependent memory was explored in the spontaneous alternation task (SAT), which has been widely used as a measure of spatial working memory, and associated with induction of theta rhythm activity within the septohippocampal pathway (McNaughton and Feldon 1980; Givens et al. 1992; Stefani and Gold 1998; Smith and Pang 2005; Cisse et al. 2008). Rats were tested in the SAT following infusion of R3/I5 and/or R3(B $\Delta 23-27) \mathrm{R} / \mathrm{I} 5$ into the MS, and percent alternation scores were used to assess spatial working memory. Levels of neuronal activation in the NI of naïve, handled, and SAT-exploring rats were also evaluated using c-Fos immunohistochemistry, to establish that RLN3-producing NI neurons were active during the behavioral test.

In light of the physiological and behavioral data, the existence of close, "synaptic" contacts of NI afferents containing RLN3-LI, with neurons in the MS containing marker proteins for GABA- and acetylcholine-neuronal phenotypes, was investigated using anterograde neural tract-tracing and conventional and fluorescence immunohistochemistry. Concurrent retrograde tract-tracing from the hippocampus was used to determine whether these MS neurons had projections to the hippocampus. Electron microscopy was also used to visualize the morphology of anterogradely labeled NI synaptic terminals in the MS.

\section{Results}

\section{R3/I5 infusion into MS enhances evoked field potentials in $\mathrm{MS}$ and hippocampus in the anesthetized rat}

Evoked field potentials in the MS and hippocampus were recorded during unilateral electrical stimulation of the fimbria in urethaneanesthetized rats, following infusion of $100 \mathrm{ng}$ of R3/I5 ( 20 $\mathrm{pmol}) \pm 200 \mathrm{ng}$ of R3(B $\Delta 23-27) \mathrm{R} / \mathrm{I} 5$ ( $\sim 40 \mathrm{pmol})$. Average evoked field potentials in the MS were significantly increased by $\sim 20 \%$, 5-10 min following local R3/I5 infusion (one-way ANOVA; $P<$ 0.05; Fig. 1A). By 30 min post-infusion, evoked potentials were not significantly different from baseline. In rats pre-infused with R3(B $\Delta 23-27) R / I 510$ min prior to R3/I5 infusion, evoked field potentials displayed a nonsignificant trend to decrease below baseline, and the R3/I5-mediated enhancement was blocked by the pretreatment $(P<0.05)$. Similarly, evoked potentials in the hippocampus were significantly increased by $30 \%-40 \%$, 2-10 min following infusion of R3/I5 into the MS, compared to baseline $(P<0.05$; Fig. $1 \mathrm{~B})$, and 10 -min pre-infusion with R3(B $\Delta 23-27) \mathrm{R} / \mathrm{I} 5$ significantly reduced this effect $(P<0.05)$.

\section{R3/I5 infusion into MS enhances hippocampal theta activity in the anesthetized rat}

Hippocampal EEG recordings in the anesthetized rat revealed a predominance of slow waves due to urethane anesthesia under spontaneous conditions, with very little theta frequency activity. Infusion of R3/I5 into the MS resulted in significantly increased spontaneous theta activity 5-10 min after infusion, compared to baseline control (one-way ANOVA; $P<0.01$; Figs. 1C and 2). By $30 \mathrm{~min}$, theta activity was no longer significantly different from baseline. This effect was significantly attenuated in rats that were pre-infused with R3(B $\Delta 23-27) R / I 510$ min prior to R3/I5 infusion $(P<0.01$ at $t=5 \mathrm{~min}$ and $P<0.05$ at $t=10 \mathrm{~min}$; Fig. 1C), where theta activity was not significantly different from baseline throughout the 30-min recording. Slower delta activity was decreased following infusion, although this was not statistically significant (Fig. 2).

In separate experiments, theta rhythm was evoked by electrical stimulation of the RPO (Nuñez et al. 2006). Trains of electrical activity (40-100 $\mu \mathrm{A}, 50 \mathrm{~Hz}$ for $500 \mathrm{msec})$ in the RPO significantly increased theta rhythm in the hippocampus compared to a 3-min 
A
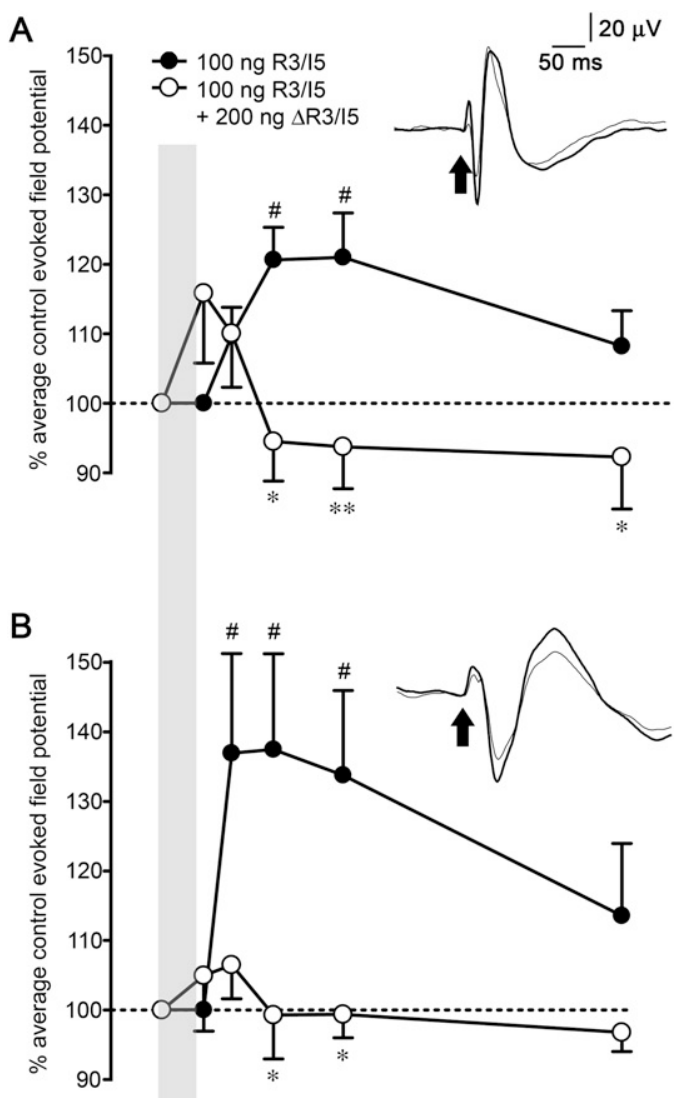

C

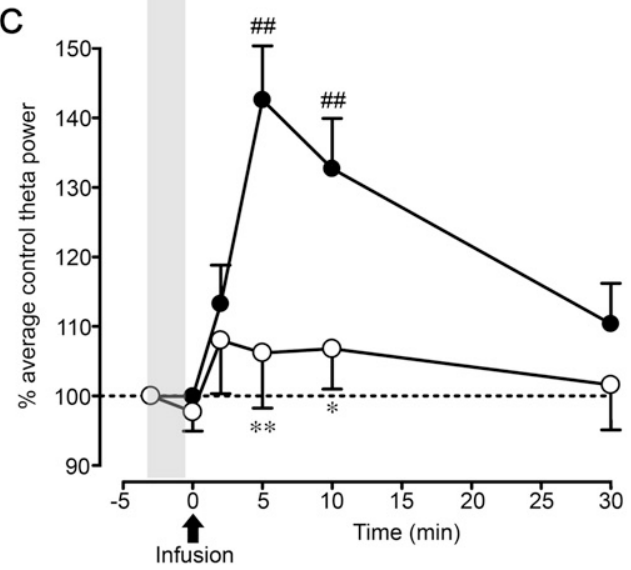

Figure 1. Effects of $R 3 / 15 \pm R 3(B \Delta 23-27) R / 15(\Delta R 3 / 15)$ infusions into the MS on hippocampal and MS field potential recordings in anesthetized rats. Infusions of $100 \mathrm{ng}$ of R3/15 (•) into the MS resulted in a significant increase in evoked field potentials in the $(A) \mathrm{MS}$ and $(B)$ hippocampus during electrical stimulation of the contralateral fimbria $(n=14)$ and $(C)$ significantly increased the average power of hippocampal theta activity $(n=10)$, compared to 3 -min control activity (shaded) recorded in the anesthetized rat. Data were normalized within each rat as a percentage of control activity recorded $3 \mathrm{~min}$ prior to infusions (shaded). These effects were significantly attenuated by 10 -min pre-infusion of $200 \mathrm{ng}$ of $\Delta \mathrm{R} 3 / 15$ $(\bigcirc)$ into the MS $(n=6-8)$. Data were averaged from sessions of 60 pulses at $1 \mathrm{~Hz}$. Raw traces of evoked field potentials illustrating the effect of R3/15 (thick black line) in the MS (inset $A$ ) and hippocampus (inset $B$ ), compared to control (thin gray line). (Arrows) Time of infusion. $\left({ }^{*}\right) P<0.05$ compared to R3/15; (**) $P<0.01$ compared to R3/15; (\#) $P<0.05$ compared to 3-min control recording; (\#\#) $P<0.01$ compared to 3-min control recording. control recording of spontaneous activity after infusion of saline into the MS $(P<0.05$; Fig. 3). Two hours were allowed to elapse before another 3-min control recording was taken, which revealed that theta activity had returned to baseline and was not different from that observed prior to RPO stimulation. Infusion of $200 \mathrm{ng}$ of $\mathrm{R} 3(\mathrm{~B} \Delta 23-27) \mathrm{R} / \mathrm{I} 510 \mathrm{~min}$ prior to a second train of RPO stimulation resulted in $\sim 30 \%$ attenuation of theta generation, compared to saline infusion (repeated-measures one-way ANOVA; $P<0.05$; Fig. 3 ).

\section{$\mathrm{R} 3 / \mathrm{I5}$ and $\mathrm{R} 3(\mathrm{~B} \Delta 23-27) \mathrm{R} / \mathrm{I5}$ infusions into the MS differentially modulate hippocampal theta activity in the awake rat}

Field potential recordings of the hippocampus in the conscious rat displayed greater variability than in the anesthetized rat. In a rat sitting quietly in its home cage, theta activity was relatively low following infusion of aCSF into the MS compared to that observed following infusion of aCSF and exposure to an environmentally enriched behavioral arena, where the average theta frequency power was increased by $\sim 3.5$-fold (repeated-measures one-way ANOVA; $P<0.05$; Fig. 4A). Rats displayed high levels of exploration of the objects in the arena, which was reflected by increased activity counts and core body temperature compared to readings taken in the home cage (Fig. 4E,F). Behaviors observed during exploration of the arena included rearing, grooming, and digging, and numerous object interactions including sniffing, climbing onto objects, and pushing objects to different locations within the arena. Activity counts were, at most, approximately threefold higher in the behavioral arena compared to the home cage (Fig. $4 \mathrm{E})$. Infusions of R3/I5 (200 ng, $\sim 40 \mathrm{pmol})$ or R3(B $\Delta 23-27) \mathrm{R} / \mathrm{I} 5$ (400 ng, $\sim 80 \mathrm{pmol}$ ) into the MS had no significant effect on activity or body temperature in either home cage or behavioral arena, respectively $(P>0.05$; Fig. $4 \mathrm{E}, \mathrm{F})$.

In light of the theta-promoting effects of R3/I5 in the anesthetized rat, R3/I5 was infused into the MS of rats that were placed back into their home cage for recording, where theta activity is usually low. R3/I5 [or R3(B $\Delta 23-27) \mathrm{R} / \mathrm{I} 5$ ] or aCSF vehicle was infused on day 1 , and a cross-over infusion was made on day 2 , which established a baseline control recording by which we were able to compare the effects of R3/I5 or R3(B $\Delta 23-27) \mathrm{R} / \mathrm{I} 5$ within individual rats. The average theta frequency power following aCSF infusion was increased compared to pre-infusion $(P<0.05$; Fig. $4 \mathrm{~B}$ ), which may have resulted from handling and when the rat briefly reacclimatized to its home cage. R3/I5 infusion further increased theta frequency power by $28.4 \% \pm 9.16 \%$ compared to aCSF infusion over $30 \mathrm{~min}(P<0.05$; Fig. 4B). Analysis of raw EEG data obtained from a rat prior to infusion showed primarily asynchronous activity, which, following infusion of aCSF, showed some theta activity with asynchronous activity (Fig. 4D). Following infusion of R3/I5 into the MS, strong theta rhythm was observed, particularly 5-10 min post-infusion (Fig. 4D).

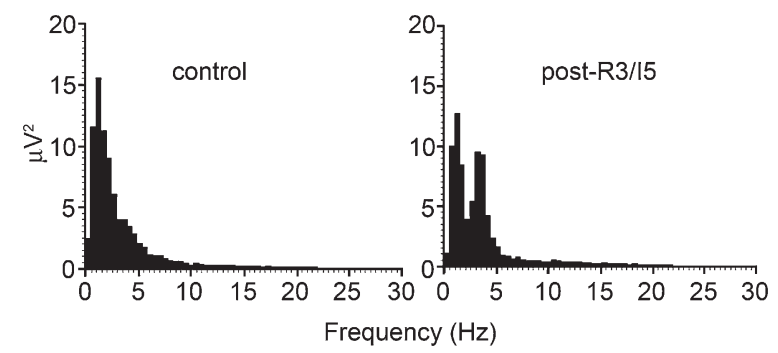

Figure 2. Power spectra of hippocampal field activity from experiment shown in Figure 1, illustrating increased hippocampal theta activity following R3/15 infusion into the MS. 


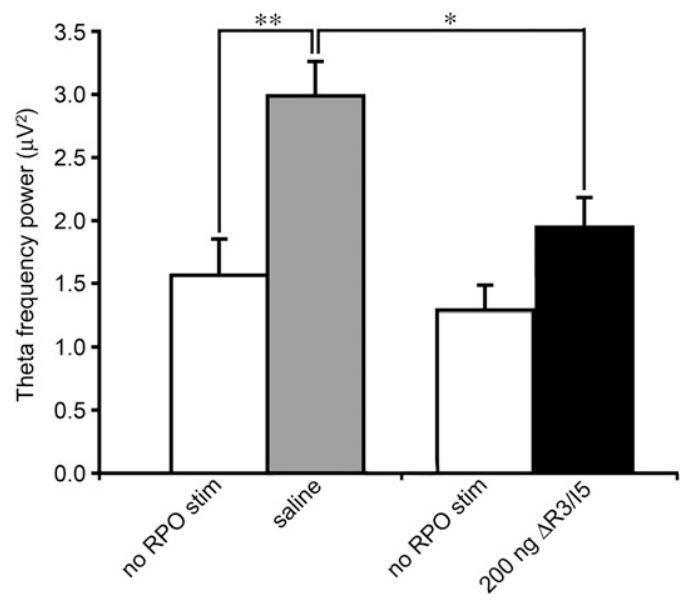

Figure 3. Effect of $R 3(B \Delta 23-27) R / 15(\Delta R 3 / 15)$ infusion into the $M S$ on RPO stimulation-induced hippocampal theta activity in anesthetized rats. Average hippocampal theta activity was significantly increased by electrical stimulation of the RPO following saline infusion into the MS (gray bar), compared to spontaneous activity recorded prior to RPO stimulation (white bars). This effect was significantly attenuated following 10-min pre-infusion of $200 \mathrm{ng}$ of $\triangle \mathrm{R} 3 / 15$ into the MS (black bar) prior to a second train of RPO stimulation $(n=9) .\left(^{*}\right) P<0.05 ;\left({ }^{*}\right) P<0.01$.

Likewise, because R3(B $\Delta 23-27) R / I 5$ had theta-reducing effects in the anesthetized rat, infusions of the antagonist into MS in a separate group of rats were made $10 \mathrm{~min}$ prior to 30 -min exposure to the behavioral arena, where theta activity is elevated, for recording in a similar cross-over design. The average theta frequency power following R3(B $\Delta 23-27) \mathrm{R} / \mathrm{I} 5$ infusion was significantly decreased by $24.5 \% \pm 7.20 \%$ compared to aCSF infusion (P<0.05; Fig. 4C).

\section{$\mathrm{R} 3(\mathrm{~B} \Delta 23-27) \mathrm{R} / \mathrm{I5}$ impairs spatial working memory performance in the spontaneous alternation task}

The effect of RLN3/RXFP3 signaling in the MS on a "thetadependent" behavior was investigated in rats in the SAT, a behavioral test using a four-closed-arm plus-maze that has been used extensively to quantify spatial working memory in rodents (Stefani and Gold 1998; Lalonde 2002; Cisse et al. 2008). The average number of arm entries made by rats across all treatment groups was not significantly different, indicating that the infusions of agonist and antagonist into the MS did not affect locomotor ability or cause hyper- or hypoactivity (Supplemental Table 1). The percent alternation score (PAS) of aCSF-infused control rats was $75.5 \% \pm 3.10 \%$ (Fig. 5), which, while relatively high, is similar to that reported in previous studies (Stefani and Gold 1998). Higher PAS was interpreted as indicating better alternation and therefore better spatial memory performance. Rats infused with various concentrations of R3(B $\Delta 23-27) R / I 5$ (100-400 ng, 20-80 pmol) into the MS $10 \mathrm{~min}$ prior to the SAT revealed a dosedependent decrease in PAS (one-way ANOVA; $P<0.05$; Fig. 5), where the highest dose of $400 \mathrm{ng}$ resulted in a highly significant impairment of performance $(52.6 \% \pm 1.49 \% ; P<0.001)$. In rats that received a combined infusion of $400 \mathrm{ng}$ of R3(B $\Delta 23-27) \mathrm{R} / \mathrm{I} 5$ and 400 ng of R3/I5, R3(B $\Delta 23-27) \mathrm{R} / \mathrm{I} 5$-induced impairment was restored to a performance equivalent to that observed after aCSF infusion $(75.4 \% \pm 3.34 \%)$ and was significantly greater than that of $400 \mathrm{ng}$ of R3(B $\Delta 23-27) \mathrm{R} / \mathrm{I} 5$-infused rats $(P<0.001$; Fig. 5). Groups of rats infused with $200-400$ ng of R3/I5 had no statistically
A

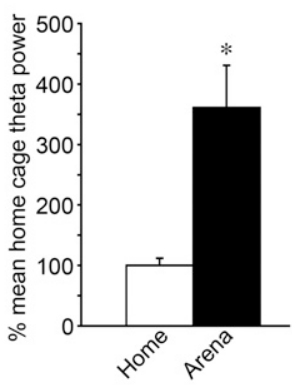

D

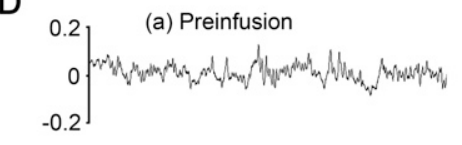

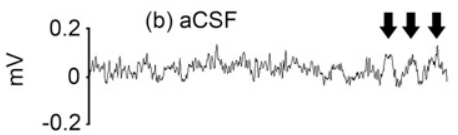

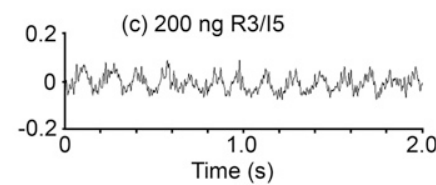

B

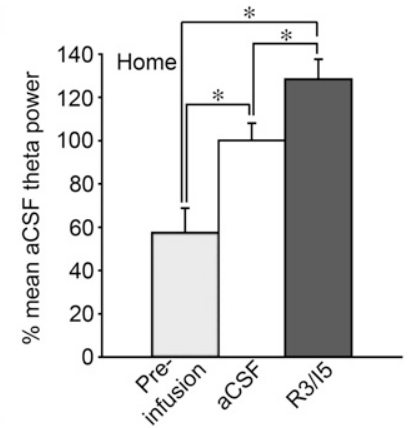

E

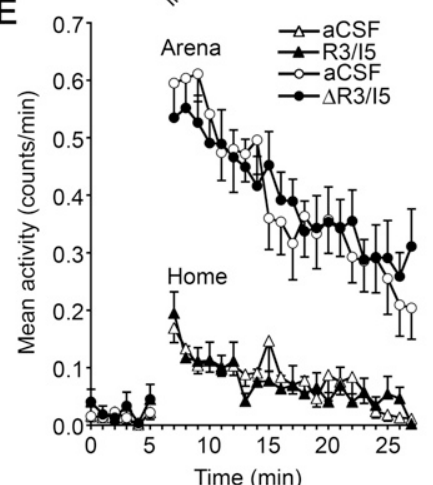

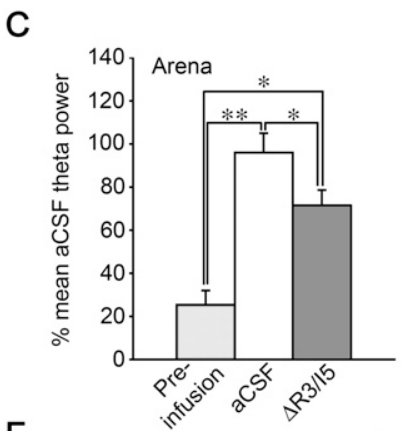

$\mathrm{F}$

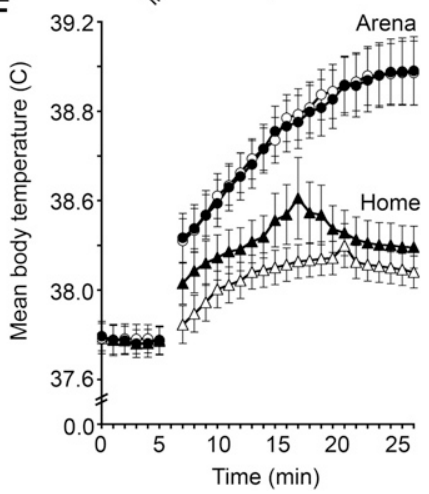

Figure 4. Effects of $R 3 / 15$ and $R 3(B \Delta 23-27) R / 15(\Delta R 3 / 15)$ infusions into the $M S$ on hippocampal EEG recordings in conscious rats assessed using telemetry. $(A)$ The average power of hippocampal theta activity was significantly elevated in awake rats exposed to an environmentally enriched behavioral arena $(n=6)$ compared to home cage $(n=3)$. The average power of theta activity was $(B)$ significantly increased following infusion of $200 \mathrm{ng}$ of $\mathrm{R} 3 / 15$ into the MS of rats in their home cage compared to aCSF infusions ( $n=11-12 /$ group) and (C) significantly decreased following infusion of $400 \mathrm{ng}$ of $\Delta \mathrm{R} 3 / 15$ into the MS of rats exposed to the behavioral arena ( $n=16-17 /$ group). Both aCSF and peptide levels were significantly above pre-infusion levels (see Results). (D) Representative raw EEG trace from an individual rat that was (a) undisturbed in home cage, prior to (b) infusion of aCSF or (c) $200 \mathrm{ng}$ of $\mathrm{R} 3 / \mathrm{I5}$ into the MS. Infusions of either R3/I5 or $\triangle \mathrm{R} 3 / \mathrm{I5}$ into the MS had no significant effect on $(E)$ activity counts and $(F)$ body temperature of rats in home cage or behavioral arena. $\left(^{*}\right) P<0.05 ;\left({ }^{*}\right) P>0.01$. 


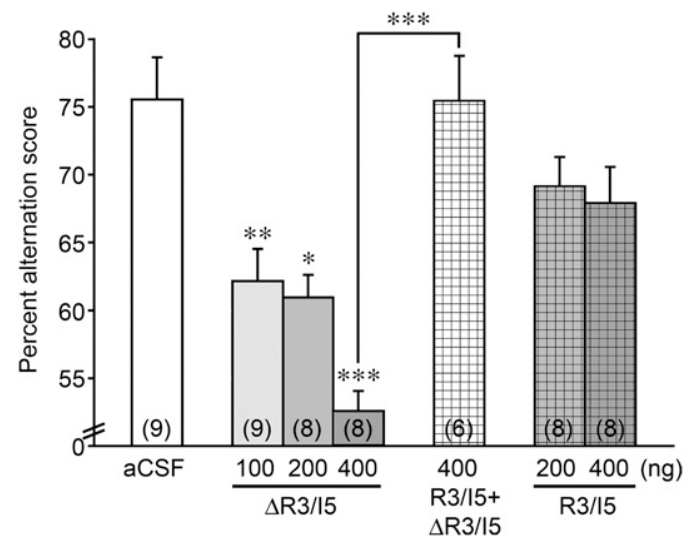

Figure 5. Effects of $R 3 / 15$ and $R 3(B \Delta 23-27) R / 15(\Delta R 3 / 15)$ infusions into the MS on spatial working memory performance assessed in a SAT. Percent alternation score (PAS) of experimental groups in the SAT following 10-min pre-infusions of aCSF (white bar; $n=9$ ), increasing concentrations of $\Delta \mathrm{R} 3 / 15$ (shaded bars; $n=8-9 /$ group), co-infusion of 400 ng each of $\mathrm{R} 3 / 15+\Delta \mathrm{R} 3 / 15$ (hatched bar; $n=6$ ), and two concentrations of R3/15 (shaded hatched bars; $n=8 /$ group). $\left(^{*}\right) P<0.05 ;\left(^{* *}\right) P<0.01$; $(* *)) P<0.001$

significant difference in PAS $(69.1 \% \pm 2.15 \%$ and $67.9 \% \pm 2.66 \%$, respectively) compared to the aCSF group ( $P>0.80$; Fig. 5).

\section{SAT activity activates NI RLN3 neurons}

Immunohistochemical staining for c-Fos was used as a measure of neuronal activation in coronal sections of NI from rats in the aCSF control group that were killed as naïve, or $1 \mathrm{~h}$ after handling, or a 10-min exposure to the SAT apparatus. Quantification of the average number of c-Fos-positive nuclei (mean density of nuclei/ $\mu \mathrm{m}^{2} \times 10^{3}$; averaged from three sections per rat) demonstrated an increase of approximately threefold in the handled group $\left(1.71 \pm 0.91\right.$ nuclei $/ \mu \mathrm{m}^{2}$; one-way ANOVA; $P<0.05$; Fig. $\left.6 \mathrm{E}\right)$ and an increase of approximately fivefold in the SAT group $(2.88 \pm$ $0.35 ; P<0.01$; Fig. $6 \mathrm{~B}, \mathrm{E})$ compared to naïve levels $(0.57 \pm 0.26$; Fig. $6 \mathrm{~A}, \mathrm{E})$.

Double-labeling for c-Fos and RLN3 was performed in a separate series of sections using immunofluorescence (Fig. 6C-E). Although antibodies against RLN3 and c-Fos were both generated in rabbit, extensive washing was performed between sequential primary antibody steps to minimize any cross-reaction. Moreover, RLN3-LI was confined to the neuronal cytoplasm, whereas c-Fos-LI was confined to the nucleus, which confirms the specificity of the double-label staining observed. The proportion of c-Fos/RLN3positive neurons of the total number of RLN3-LI neurons was marginally increased in rats that were handled compared to naïve levels, although this was not statistically significant $(13.4 \%$ and $6.8 \%$, respectively; one-way ANOVA; $P=0.62$; Fig. $6 \mathrm{C}, \mathrm{E}$ ). SAT-run rats displayed a significantly higher proportion of c-Fos/RLN3positive neurons (46.1\%) compared to the handled and naïve groups (one-way ANOVA; $P<0.001$; Fig. 6D,E). Quantification of c-Fos-LI present in RLN3-negative cells as a percentage of the total number of RLN3-LI neurons revealed a small increase from naïve levels (1.1\%) after handling (2.6\%) and SAT activity (2.8\%), although this was not statistically significant (one-way ANOVA; $P=0.18)$.

\section{Anterogradely labeled NI fibers and RLN3-positive fibers and terminals contact soma and processes} of intrinsic and hippocampal projection neurons in MS The neuronal populations in MS targeted by RLN3/NI projections were explored using a series of double-immunolabeling studies.
Boutons and terminations of NI neuronal afferents in MS, anterogradely labeled with miniruby ( $\mathrm{mR}$ ), and those immunoreactive for RLN3, were examined for close contacts with cell bodies and processes of septal neurons immunoreactive for calcium-binding proteins, such as calbindin, and with hippocampal projecting neurons labeled with fluorogold (FG). In the diagonal band, anterogradely labeled fibers resulting from restricted $\mathrm{mR}$ injections in NI ran vertically and horizontally in the vertical and horizontal limbs, respectively. Some labeled fibers gave rise to tufted terminal-like labeling. In the vertical limb of MS, terminal-like labeling formed dense plexuses in a band located in the transition between the medial and the lateral septum and appeared to make close contact with cells retrogradely labeled from the hippocampus with FG (Fig. 7A). This labeling band contained a dense population of calbindin-positive cells and processes (Fig. 7B). In the horizontal limb of the diagonal band, terminal-like labeling formed dense plexuses in two bands one just beneath the pial surface and the other in the deepest layer at the border between the horizontal diagonal band and the nucleus accumbens. There was a central band in the horizontal limb that was in continuity with the innermost band of the vertical limb and contained a lower density of labeled fibers. Most of these fibers displayed nonterminal-like morphologies.
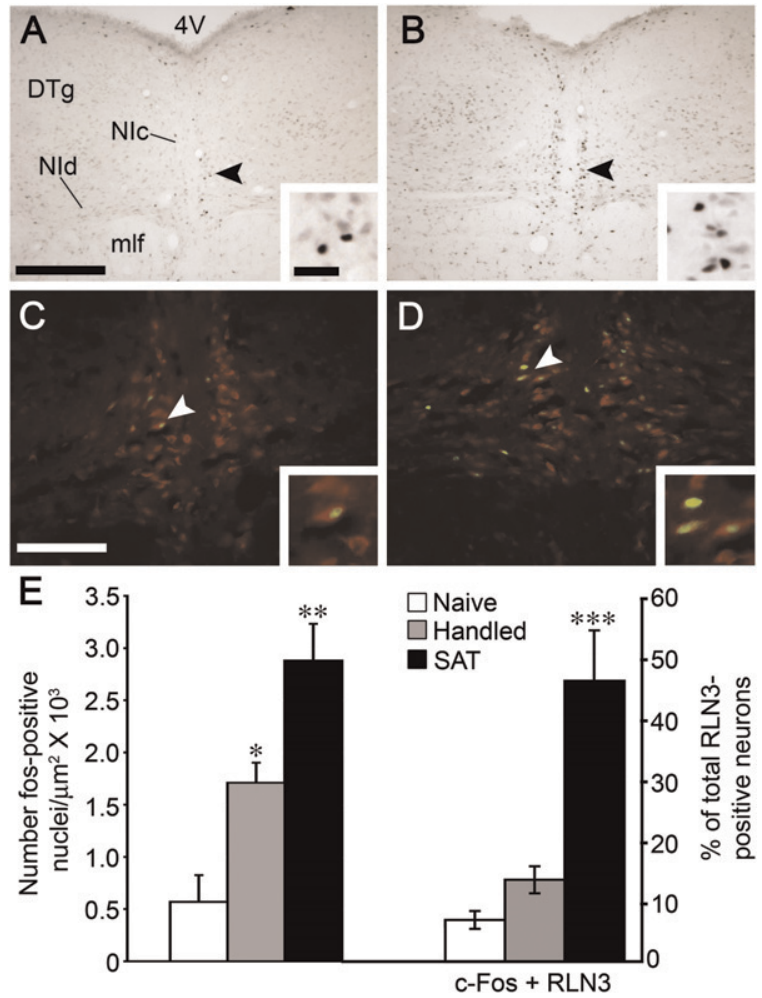

Figure 6. SAT activity increases the number of c-Fos-positive RLN3 neurons in the NI. Representative photomicrographs of c-Fos-immunostaining in coronal sections of the $\mathrm{NI}$ from a $(A)$ naïve rat and $(B)$ a rat exposed for $10 \mathrm{~min}$ to the SAT. Double-lable immunostaining for c-Fos (green) and RLN3 (red) confirm that RLN3 neurons express different levels of Fos-IR in a (C) naive rat and $(D)$ a rat exposed for 10 min to the SAT. (E) Quantification of the average number of c-Fos-positive nuclei and percent c-Fos + RLN3 neurons in the NI of naive, handled, and 10-min SATexposed rats ( $n=3 /$ group). ${ }^{*} P<0.05 ;{ }^{* *} P<0.01$. $4 \mathrm{~V}$, fourth ventricle; DTg, dorsal tegmental nucleus; NIc, nucleus incertus, compact part; NId, nucleus incertus, diffuse part; mlf, medial longitudinal fasciculus. Scale bars $=0.3 \mathrm{~mm}(A, B)$ and $45 \mu \mathrm{m}$ (inset and $C, D)$. ${ }^{* *} P<0.0001$. 


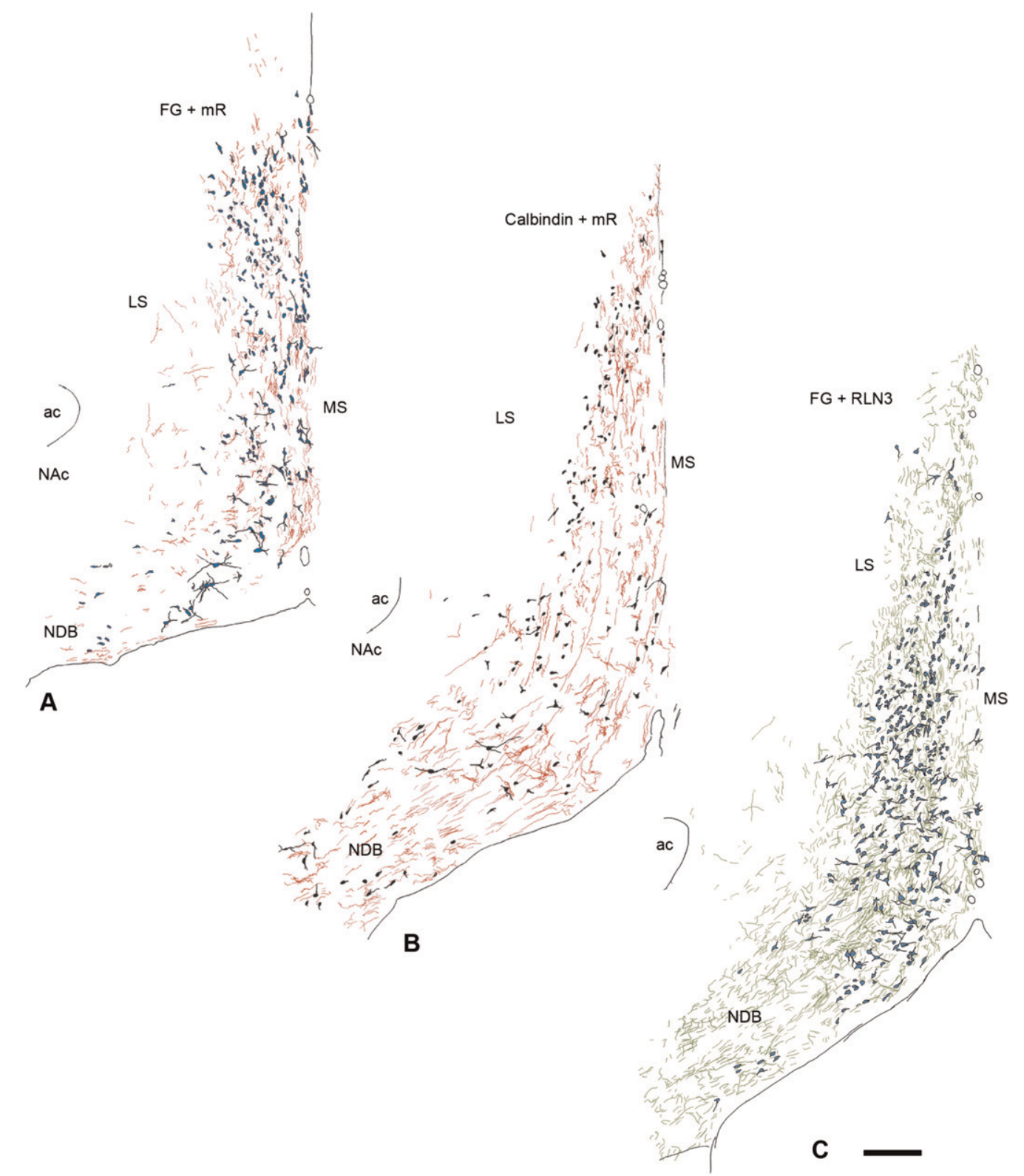

Figure 7. Neuroanatomical characterization of RLN3-positive and NI-efferent projections in the rat MS. Camera lucida drawings of the MS illustrate the distribution of $\mathrm{mR}$ anterogradely labeled projection fibers from the $\mathrm{NI}$ (red) combined with $(A) \mathrm{FG}$ retrogradely labeled cell bodies from the hippocampus (blue), and (B) calbindin-Ll cell bodies (black). (C) Camera lucida drawings revealed a good correlation of the distributions of RLN3-LI fibers (green) and FG retrogradely labeled cell bodies (blue) in the MS. (ac) Anterior commissure; (LS) lateral septum; (MS) medial septum; (NAc) nucleus accumbens; (NDB) nucleus of the diagonal band. Scale bar, $0.2 \mathrm{~mm}$.

Most RLN3 fibers displayed shorter trajectories and in some cases displayed tufted morphologies (Fig. 7C). As observed following anterograde labeling, RLN3-LI fibers formed denser plexuses in the MS borders with the lateral septum and nucleus accumbens, and a thinner band was present beneath the pial surface of the horizontal limb of the diagonal band (Fig. 7C). Thus, the pattern of RLN3-LI in the MS correlated well with that observed following anterograde tract-tracing of neuronal projections from the NI. Double-labeling of RLN3 and FG revealed that RLN3-LI fibers made close contact with soma and proximal processes of FGpositive neurons (Figs. 7C and 8). Additional double-labeling studies revealed close contacts of RLN3-positive terminals with neurons that were immunoreactive for parvalbumin and calreti- nin and with choline acetyltransferase-positive cells (data not shown). A more quantitative description of these cells and their distribution throughout the MS and adjacent areas is being prepared (FE Olucha-Bordonau, S Ma, and AL Gundlach, in prep.).

\section{Triple-immunolabeling of anterogradely labeled fibers from $\mathrm{NI}$, retrogradely labeled neurons from hippocampus, and RLN3-LI terminals in MS}

Neurons retrogradely labeled from the dorsal hippocampus with FG were observed in the inner part of both vertical and horizontal limbs of the diagonal band and MS (Figs. 7 and 8). RLN3-LI was observed in many anterogradely labeled fibers in these regions, 

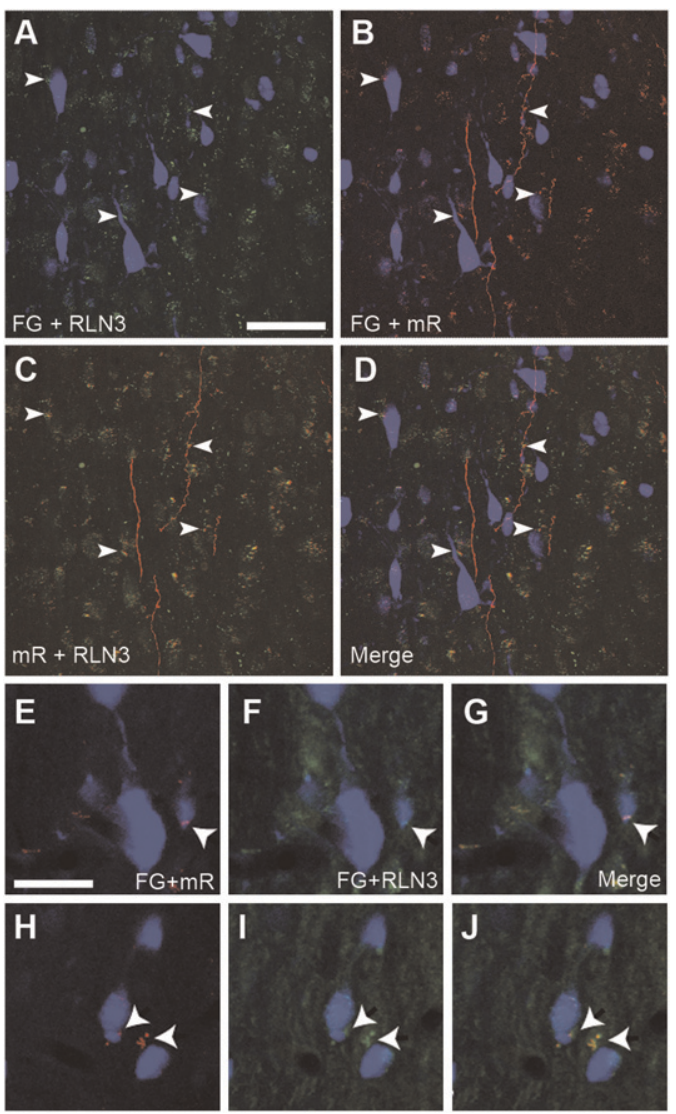

Figure 8. Confocal photomicrographs of triple-label immunofluorescence in coronal sections of the MS illustrating cell body staining following retrograde labeling with FG (blue) injected into the hippocampus, RLN3-LI fibers and terminations labeled with FITC (green), and anterogradely labeled fibers and terminations labeled by $\mathrm{mR}$ injection into the $\mathrm{NI}$ ( $\mathrm{mR}$; red). (A) Numerous RLN3-positive terminations were observed to make close contacts with FG-labeled cell bodies and proximal processes (white arrows), which corresponded with $(B, C) \mathrm{mR}$ anterogradely labeled terminations. (D) Merge of images in $A-C$. $(E-C, H-f)$ Series of high-magnification photomicrographs of septal FG-labeled neurons with close contacts with mR- and RLN3-positive terminals. Scale bars, $(A-D) 60 \mu \mathrm{m} ;(E-J) 20 \mu \mathrm{m}$

and in many cases, these fibers made close contact with retrogradely labeled neurons from the hippocampus (Figs. 7 and 8). Anterograde $\mathrm{mR}$ labeling from the NI was observed around the soma and dendritic shafts of these neurons.

\section{Electron microscopy of anterogradely labeled fibers from the $\mathrm{NI}$ in the MS}

Myelinated fibers containing mR-associated reaction product were observed in medial regions of MS. Although the presynaptic morphology was partially masked by the reaction product, it was possible to observe densely packed synaptic vesicles, some with oval morphologies (Fig. 9, white arrows). Some labeled terminals also contained large dense vesicles. Labeled terminals made contact with primarily dendritic shafts and small spines with clear symmetric morphology (Fig. 9, black arrows).

\section{Discussion}

This is the first study to demonstrate a function of endogenous RLN3 in cognition, identifying the modulation of hippocampal theta activity and spatial memory by septal RLN3 signaling in rats.
In anesthetized and conscious rats, activation of RXFP3 in the MS enhanced evoked potentials of the MS and hippocampus and promoted rhythmic membrane potential oscillation at theta frequency, while the reverse was observed if septal RXFP3 were blocked by R3(B $\Delta 23-27) R / I 5$. Furthermore, we have obtained evidence that endogenous RLN3 signaling in the MS is associated with a theta rhythm-dependent process, spatial working memory. Rats infused with R3(B $\Delta 23-27) R / I 5$ displayed a dose-dependent decrease in percent alternation score (i.e., spatial memory performance) in the spontaneous alternation test, which was "reversed" in rats that received coinfusion of equimolar concentrations of R3/ I5 and R3(B $\Delta 23-27) R / I 5$. Septal infusions of R3/I5 had no significant effect on performance in the SAT, which could be due to the availability of sufficient spatial cues to allow maximal performance, resulting in a "ceiling effect" in the assay, or to high levels of endogenous RLN3 neurotransmission from activated NI neurons. In this regard, future studies could investigate the capability of R3/I5 to alleviate pharmacologically induced deficits in spatial memory (Givens et al. 1992; Stefani and Gold 1998) or naturally occurring (age-related) cognitive impairments that are known to be a result of decreased hippocampal theta activity (Asaka et al. 2005; Cummins and Finnigan 2007; Cummins et al. 2008).

Neuronal activity in the NI reflected by c-Fos-LI was increased following SAT activity, compared to levels after handling alone and in naïve rats, which were comparably low. Double-label immunofluorescence revealed that approximately half of RLN3LI neurons showed increased c-Fos-LI following SAT activity, compared to handled and naïve rats. NI neurons containing c-Fos-LI but not RLN3-LI were sparse and marginally increased following handling and SAT activity. These data suggest a role of endogenous septal RLN3 signaling in spatial memory processing, presumably through effects on pacemaker neurons and the modulation of hippocampal theta rhythm. In contrast, we have observed in preliminary experiments that septal infusions of similar amounts of $\mathrm{R} 3 / \mathrm{I} 5$ or $\mathrm{R} 3(\mathrm{~B} \Delta 23-27) \mathrm{R} / \mathrm{I} 5$ in rats had no marked effect on emotional memory, assessed using an inhibitory avoidance test (see Ma et al. 2005; S Ma and AL Gundlach, unpubl.). The possible specificity of septal RLN3 signaling on spatial memory is consistent with findings demonstrating a specific role of septal hyperpolarization-activated cyclic nucleotidegated channels in promoting hippocampal theta generation and spatial working memory, but no effect on emotional memory (Cisse et al. 2008).
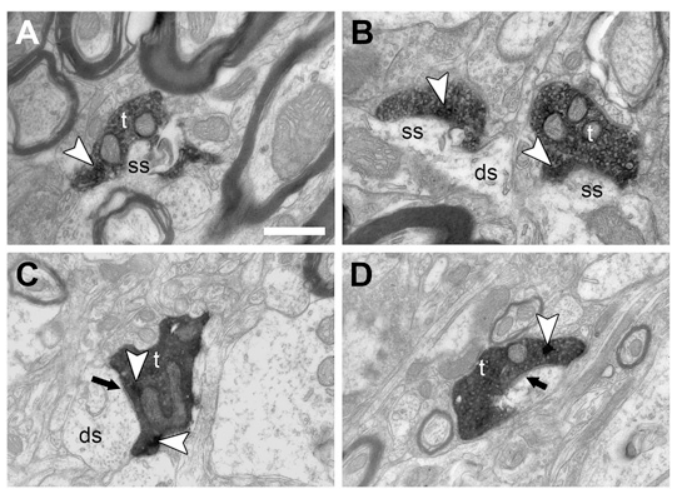

Figure 9. Electron photomicrographs of coronal sections of the MS following anterograde-labeling from the $\mathrm{NI}$ after local injection of $\mathrm{mR}$. $(A-D)$ Densely packed synaptic vesicles of oval morphology were observed in terminal synapses (white arrows), many of which made contact with dendritic shafts and small spines of MS neurons with clear symmetric morphology (black arrows). (ds) Dendritic shaft; (ss) small spine; (t) terminal. Scale bar, $500 \mathrm{~nm}$. 
Our demonstration that RLN3 signaling in MS is associated with activation of theta in the septohippocampal pathway and alteration of SAT performance is consistent with earlier findings that intraseptal galanin injections impaired T-maze alternation performance and decreased hippocampal theta rhythm (Givens et al. 1992), although cholinergic neurons are presumed to be the major target neurons for this inhibitory peptide, whereas RLN3 is likely to more strongly alter the activity of septal GABA neurons rather than, or in addition to, cholinergic neurons. This view is based on the dispersed and punctate distribution of RXFP3 mRNA in several brain areas (Sutton et al. 2004; Ma et al. 2007), consistent with its expression by GABA neurons, and on data from experiments in which pretreatment of rats with atropine (10 $\mathrm{mg} / \mathrm{kg}$, i.p.) failed to significantly alter the activation of theta rhythm by septal R3/I5 infusion (A Nuñez, S Ma, SW Sutton, and AL Gundlach, unpubl.). Septal cholinergic neurons appear to have a secondary role to GABAergic neurons in theta generation in vivo (Wu et al. 2000; Henderson et al. 2004; Simon et al. 2006; Hangya et al. 2009), although further studies are required to clarify the relative degree of involvement of GABAergic and cholinergic signaling in RXFP3 activation or inhibition in the MS.

It is well established that hippocampal theta rhythm underlies various forms of mnemonic processing (Klimesch 1999; Hasselmo 2005; Vertes 2005) and that "pacemaker" regions, such as the MS, are involved in the generation and maintenance of this unique oscillatory neuronal firing (Vertes and Kocsis 1997; Wang 2002). It is also well established that hippocampal theta rhythm is dependent on the integrity of an ascending pathway originating from the brainstem reticular formation and that the RPO is an effective theta-generating nucleus of the brainstem (Nuñez et al. 1991; Vertes et al. 1993). The RPO, however, does not have direct projections to the MS and other subcortical pacemaker regions (Vertes and Fass 1988). Recent evidence suggests that brainstemgenerated theta rhythm occurs through a multisynaptic pathway via the NI (Nuñez et al. 2006; Teruel-Marti et al. 2008), which has strong connectivity with the MS, SuM, and interpeduncular nuclei, and with the hippocampus itself (Goto et al. 2001; Olucha-Bordonau et al. 2003); and lesion or muscimol inactivation of the NI abolishes RPO-stimulated theta activity (Nuñez et al. 2006).

In this study, we demonstrated that RLN3-LI in the MS originates from the NI and used immunohistochemistry to demonstrate close synaptic contacts of RLN3-LI boutons with GABAergic (and cholinergic) neurons in MS, including those that project to the hippocampus and local interneurons that are immunopositive for calbindin and calretinin (Kiss et al. 1990, 1997; Gulyas et al. 2003). Since the neurochemical and electrophysiological properties of the various types of septal neurons involved in theta generation are becoming established (Simon et al. 2006), further characterization of the septal neurons involved in RLN3/RXFP3 signaling should be possible, particularly if a specific antibody to RXFP3 becomes available that can identify the receptor in vivo. The present study suggests, however, that RLN3/RXFP3 signaling can alter GABAergic and, to some extent, cholinergic neuron activity, and such effects underlie the effects of R3/I5 and R3(B $\Delta 23-27) R / I 5$ on theta and spatial working memory observed. Neural tract-tracing experiments indicate that RLN3-LI boutons make close synaptic contact with the dendrites and soma of neurons that project to the hippocampus, which are known to be GABAergic and cholinergic in nature (Vertes and Kocsis 1997; Wang 2002; Simon et al. 2006). Most, if not all, RLN3 neurons in the NI are GABAergic (Ma et al. 2007). Ultrastructural analysis of anterogradely labeled NI terminations in the MS, using electron microscopy, demonstrated that labeled synapses were generally symmetric in morphology and contained large, oval, synaptic vesicles, which is indicative of inhibitory synapses (Peters and
Palay 1996) and is consistent with colocalization of RLN3 and GABA in NI efferents. The relationship between RLN3 and GABA neurotransmission is unclear and remains to be investigated.

RXFP3 was initially characterized as functionally coupled to the inhibition of cAMP (Liu et al. 2003), but more recent studies have identified that RXFP3 stably expressed in Chinese hamster ovary (CHO)-K1 and human embryonic kidney (HEK)-293 cells and endogenously expressed RXFP3 in the murine SN56 septal neuron cell line activate extracellular signal-regulated kinase (ERK)-1/2 when stimulated by RLN3 (van der Westhuizen et al. 2007). ERK1/2 phosphorylation by RXFP3 activation required activation of $\mathrm{G}_{\mathrm{i} / \mathrm{o}}$ proteins and receptor internalization and/or compartmentalization and predominantly occurred via the activation of a protein kinase C-dependent pathway. Therefore, a working hypothesis might be that activation of RXFP3 on GABAergic hippocampal-projecting neurons and local interneurons in the MS would lead to a net disinhibition of principal hippocampal neurons and enhanced activity and rhythmic membrane potential oscillations. A second hypothesis may be that RXFP3 activation would increase neuronal activity in the MS via the recruitment of ERK1/2 (van der Westhuizen et al. 2007), although further studies are needed to explore this possibility and determine the precise nature of the effect of RXFP3 activation by endogenous RLN3 in the septum on the cellular physiology of the septum and hippocampus.

The NI receives dense inputs from the RPO (Teruel-Marti et al. 2008) and from a range of forebrain regions such as the prefrontal cortex, and has reciprocal connections with the lateral habenula, interpeduncular nucleus, MR, septum and diagonal band, bed nucleus of the stria terminalis, lateral hypothalamus, and amygdalohippocampal area (Goto et al. 2001; Olucha-Bordonau et al. 2003). The NI expresses receptors for CRF, and experimental studies have demonstrated CRF- and stress-induced activation of NI (Bittencourt and Sawchenko 2000) and activation of NI RLN3 neurons in response to restraint stress in rats (Tanaka et al. 2005). Our laboratory has shown that c-fos expression is increased in NI neurons following forced swim stress, and this is associated with increased levels of RLN3 expression, which are significantly attenuated in rats pretreated with the $\mathrm{CRF}_{1}$ antagonist antalarmin (Banerjee et al. 2009). These data strongly suggest that the NI could modulate theta activity and associated cognitive processes in response to stressors resulting in increased central CRF levels, and in response to arousal and motivational information processed by these cortical and limbic circuits. Furthermore, NI/RLN3 neurons have dense projections to other "pacemaker" regions, such as the SuM and interpeduncular nuclei, the MR, and the hippocampus. We anticipate that NI/RLN3 neurons modulate hippocampal function through a complex neural network, and the present findings suggest that the MS is a key part of this network.

In conclusion, these studies provide solid electrophysiological and behavioral data indicating an influence of RLN3 neurotransmission on the septohippocampal system under normal behavioral situations, such as exploration of a plus-maze. Our results are in agreement with initial hypotheses based on the anatomical connectivity of the NI that implicates this nucleus in a midline behavioral control network of the brainstem that influences attentive states, arousal, and learning processing (Goto et al. 2001; Olucha-Bordonau et al. 2003), and suggest that RLN3 makes a contribution to mediating these functions of the NI. The recent demonstration that the distribution of RLN3 in the macaque (Ma et al. 2009) is similar to that in the rat (Ma et al. 2007) suggests the existence of an equivalent system in the human brain, and supports the use of rodent studies to investigate further aspects of this network, and the implications of manipulating the RLN3/RXFP3 system for human physiology, and the treatment of cognitive and/or psychiatric dysfunction. 


\section{Materials and Methods}

\section{Materials}

R3/I5 (RLN3 B-chain/insulin-like peptide-5 A-chain) (Liu et al. 2005) and R3(B $223-27) R / I 5$ (C-terminus truncated RLN3 B-chain insulin-like peptide-5 A-chain) (Kuei et al. 2007) were synthesized as described (Haugaard-Jonsson et al. 2008; Hossain et al. 2008, 2009). Briefly, peptides were produced using solid-phase peptide synthesis and purified using RP-HPLC. The identity and purity of the peptide product were confirmed by RP-HPLC, MALDI-TOF MS, and NMR analysis, and the amino acid composition was checked. The peptide content of R3/I5 and R3(B $\Delta 23-27) \mathrm{R} / \mathrm{I} 5$ batches was $45 \%-75 \%$ and $76 \%$, respectively. R3/I5 is a selective, high-affinity RXFP3 agonist and, unlike the native peptide, does not activate

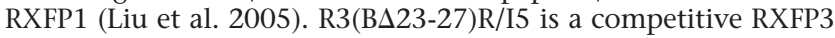
antagonist and is equipotent with R3/I5 (Kuei et al. 2007).

\section{Surgery for in vivo electrophysiology in the anesthetized rat}

Adult Sprague-Dawley rats (200-250 g; $n=6-14 /$ group) were obtained from Iffa-Credo (Saint-Aubin-lés Elbeuf, France). Rats were anesthetized with urethane $(1.6 \mathrm{~g} / \mathrm{kg}$, i.p.) and placed in a stereotaxic device (Kopf Instruments); the end-tidal $\mathrm{CO}_{2}$ was monitored by means of a capnograph. Body temperature was maintained at $37^{\circ} \mathrm{C}$ by a heating pad. Supplemental doses of the anesthetic were administered when a decrease was observed in the amplitude of the slow waves in the hippocampal field potential. Experiments were carried out in accordance with the European Communities Council Directive (86/609/EEC).

Trephine holes were drilled in the skull at preselected stereotaxic coordinates measured from bregma, according to the atlas of Paxinos and Watson (1986). Hippocampal field potential was recorded through a macroelectrode $(120 \mu \mathrm{m}$ diameter bluntly cut insulated nichrome wire), aimed at the pyramidal layer of CA1 (coordinates from bregma: $3.0 \mathrm{~mm}$ posterior, $2.0 \mathrm{~mm}$ lateral, and $3.0 \mathrm{~mm}$ ventral). MS field potential was recorded through a similar macroelectrode aimed at the midline MS (coordinates from bregma: $0.0 \mathrm{~mm}$ posterior and lateral, $7 \mathrm{~mm}$ ventral). Field potentials were filtered between 0.3 and $30 \mathrm{~Hz}$, amplified and fed to a Macintosh computer (100 Hz sample frequency) for off-line analysis. Electrical stimulation of the contralateral fimbria (coordinates from bregma: $3.6 \mathrm{~mm}$ posterior, $-4.2 \mathrm{~mm}$ lateral, and $5.0 \mathrm{~mm}$ ventral) and RPO (coordinates from bregma: $7.8 \mathrm{~mm}$ posterior, $1.2 \mathrm{~mm}$ lateral, and $7.5 \mathrm{~mm}$ ventral) was performed through bipolar electrodes (120 $\mu \mathrm{m}$ diameter bluntly cut stainless steel wire, $100 \mu \mathrm{m}$ tip separation) using rectangular pulses $(0.3$ msec, $40-100 \mu \mathrm{A})$. Stimulation trains were also applied at a frequency of $1 \mathrm{~Hz}$, and data were averaged from sessions of 60 pulses.

\section{Septal peptide infusions}

$\mathrm{R} 3 / \mathrm{I5}(200 \mathrm{ng} / \mu \mathrm{L})$ and $\mathrm{R} 3(\mathrm{~B} \Delta 23-27) \mathrm{R} / \mathrm{I5}(400 \mathrm{ng} / \mu \mathrm{L})$ were dissolved in sterile saline, and $0.5 \mu \mathrm{L}$ was injected using a $1-\mu \mathrm{L}$ Hamilton syringe stereotaxically inserted into the MS (coordinates from bregma: $0.6 \mathrm{~mm}$ anterior, $1.5 \mathrm{~mm}$ lateral, $-6.5 \mathrm{~mm}$ ventral at $15^{\circ}$ angle) to deliver $100 \mathrm{ng}$ of R3/I5 ( $\left.20 \mathrm{pmol}\right)$ or $200 \mathrm{ng}$ of $\mathrm{R} 3(\mathrm{~B} \Delta 23-27) \mathrm{R} / \mathrm{I} 5(\sim 40 \mathrm{pmol})$. One minute elapsed before the injection needle was removed to avoid reflux.

\section{Histological analysis}

Once the experiments had been completed, rats were deeply anesthetized with sodium pentobarbital $(50 \mathrm{mg} / \mathrm{kg})$ and were then transcardially perfused with saline and formalin (4\% in saline). The brain was removed, stored in $20 \%$ sucrose-saline, and sectioned with a freezing microtome. Sections of $50 \mu \mathrm{m}$ were stained with thionin to locate injection and stimulation sites.

\section{Data analysis}

Analyses of the recorded signals were performed off-line using Spike 2 software (Cambridge Electronic Design). The power spectrum of the hippocampal field activity was calculated. Periods of $60 \mathrm{sec}$ were subjected to a Fast Fourier Transformation routine, and power spectra were calculated for frequencies from 0.1 to 12 $\mathrm{Hz}$, with a resolution of $0.2 \mathrm{~Hz}$. For statistical analyses, the mean values of the following frequency bands were calculated: $0.1-3 \mathrm{~Hz}$ (delta activity) and $4-8 \mathrm{~Hz}$ (theta activity). All data are shown as mean \pm standard error of the mean (SEM). Wilcoxon matchedpairs statistics were used for comparisons.

\section{Surgery for in vivo electrophysiology with telemetry in the conscious rat}

Male Sprague-Dawley rats (300-350 g; $n=11-17 /$ group) were obtained from the Australian Research Center (Canning Vale, WA, Australia). Procedures were approved by the HFI Animal Welfare Committee, in compliance with the guidelines of the National Health and Medical Research Council of Australia. Surgical procedures were performed after $7 \mathrm{~d}$ of acclimatization to the holding facility. Rats were anesthetized by inhalation of $4 \%$ isoflurane delivered in air $(1 \mathrm{~L} / \mathrm{min})$ and positioned into a stereotaxic frame (Kopf Instruments) with anesthesia maintained by $2 \%-3 \%$ isoflurane delivered at $200 \mathrm{~mL} / \mathrm{min}$ in air using a rat anesthetic mask (Kopf Instruments). A stainless-steel guide cannula (5 mm long under pedestal, 23 gauge; Plastics One) was implanted with the cannula tip $1.5 \mathrm{~mm}$ above the MS (coordinates from bregma: 0.6 $\mathrm{mm}$ anterior, $1.5 \mathrm{~mm}$ lateral, $5.0 \mathrm{~mm}$ ventral at a $15^{\circ}$ angle), and a macroelectrode $(120 \mu \mathrm{m}$ diameter bluntly cut insulated nichrome wire) that was further insulated in silastic tubing was implanted into the dorsal CA1 level of the hippocampus (coordinates from bregma: $3.0 \mathrm{~mm}$ posterior, $2.0 \mathrm{~mm}$ lateral, and 3.0 mm ventral) (Paxinos and Watson 1986). The cannula and macroelectrode were affixed to the skull by two surgical screws and dental cement. The electrode was sutured to the back of the neck, between the scapulae, so that movement would not displace the electrode. An incision was made in the abdominal wall through linea alba, and the body of the radio transmitter (C50-PXT; DataSciences International) was placed in the peritoneum. The biopotential leads were advanced through the muscle wall and fed subcutaneously through a trochar from the abdomen to scapulae and connected to the macroelectrode. The body of the transmitter was secured into position by suturing it to the inner surface of the abdominal cavity during closure of the abdominal muscle wall. All skin incisions were closed with auto skin staples, and rats were administered postoperative analgesic and the anti-inflammatory drug meloxicam (3 mg/kg, i.p.; Troy Laboratories). Rats were placed under a heat lamp until regaining consciousness and housed individually in clean cages. During the 7 -d recovery, 0.5 $\mathrm{mg} / \mathrm{mL}$ aspirin in $5 \%$ sucrose water was made available. Rats were allowed to recover for $7 \mathrm{~d}$ before initiation of behavioral testing and were handled for 2 min per day during the $3 \mathrm{~d}$ prior to testing.

\section{Septal peptide infusions and telemetry recording}

All experiments were performed during the light phase, between 9:00 and 17:00. Radio receivers were placed under the cages or behavioral testing arena to allow recording of hippocampal EEG, body temperature, and locomotor activity by a computer system using Dataquest A.R.T. 4.1 software (DataSciences International). A 20 -min control recording was made when rats were quiet and usually sleeping, prior to any handling and septal infusions. Infusions were made with 30-gauge injector needles connected to a $10-\mu \mathrm{L}$ Hamilton syringe by polyethylene tubing. Injection needles protruded $1.5 \mathrm{~mm}$ beyond the cannula tip to reach the MS. A $0.5-\mu \mathrm{L}$ volume of R3/I5 (200 ng dissolved in aCSF) or $\mathrm{R} 3(\mathrm{~B} \Delta 23-27) \mathrm{R} / \mathrm{I5}$ (400 ng dissolved in aCSF) was infused over 60 sec by an automated syringe pump (Harvard Apparatus). The needle was left within the cannula for an additional 2 min prior to withdrawal to prevent reflux. In the R3/I5-infused group, rats were placed back into their home cage, and recording was made immediately after infusion for $30 \mathrm{~min}$. In the R3(B $\Delta 23-27) \mathrm{R} / \mathrm{I5}-$ infused group, rats were placed back into their home cage for 10 min prior to a 30-min exposure to an environmentally enriched behavioral testing arena, which consisted of a clear perspex box $(50 \mathrm{~cm} \times 50 \mathrm{~cm} \times 30 \mathrm{~cm}$ high) lined with litter and containing a small cardboard box, three short pieces of cardboard tubing, and 
red and blue tube lids. A crossover experimental design was used to establish a control recording for each rat, where either drug or aCSF was infused into the MS on day 1 , then on day 2 the experiment was repeated with either aCSF or drug infusion. Each experiment consisted of approximately equal numbers of peptide and aCSF-infused rats.

\section{Histological analysis}

On day 3, rats were deeply anesthetized by isoflurane inhalation and decapitated. The brain was rapidly removed and frozen on dry ice, and coronal sections of $20 \mu \mathrm{m}$ were stained with thionin to confirm cannula and electrode placement. Only data from rats with correct cannula and electrode placements were analyzed.

\section{Data analysis}

Statistical analyses of the recorded signals were performed offline using Dataquest A.R.T. 4.1 software (DataSciences International). The power spectrum of the hippocampal field activity was calculated from 20-min periods (pre- and post-infusion) subjected to a Fast Fourier Transformation routine. For statistical analyses, the mean values of $4-8 \mathrm{~Hz}$ (theta activity) were calculated. Within each rat, peptide-infused data were normalized as a percentage of aCSF data. All data are shown as mean \pm SEM. One-way repeatedmeasures ANOVA was used to calculate statistical significance between aCSF and drug-infused groups.

\section{Assessment of $\mathrm{NI}$ activation in the SAT}

Male Sprague-Dawley rats (300-350 g; $n=6-9 /$ group) were obtained from the Australian Research Center, and cannula implantation targeting the MS was performed as described. Rats were allowed to recover for $7 \mathrm{~d}$ before initiation of behavioral testing and were handled for 2 min per day on the $3 \mathrm{~d}$ prior to testing.

The SAT was conducted using a closed plus-maze as described (Stefani and Gold 1998). Each arm was $75 \mathrm{~cm}$ long and $10 \mathrm{~cm}$ wide, with $17-\mathrm{cm}$-high walls. The maze floor was washed with $70 \%$ ethanol between animals. Spatial cues in the testing room were minimized as much as possible. Infusions of $0.5-\mu \mathrm{L}$ volume of R3/I5 (200-400 ng dissolved in aCSF) or R3(B $\Delta 23-27) \mathrm{R} / \mathrm{I} 5$ (100$400 \mathrm{ng}$ dissolved in aCSF) were infused into the MS as described. Rats were placed back into their home cage for $10 \mathrm{~min}$ and then placed in the center of the closed plus-maze, always facing a designated arm. Rats were allowed $10 \mathrm{~min}$ of unimpeded exploration, and activity was recorded by a video camera affixed to the room ceiling. Analysis was performed offline from video recordings, and the number and sequence of arm entries were used to calculate a percentage alternation score (PAS). An alternation consisted of four different arm entries out of five consecutive arm entries. PAS was computed by dividing the number of observed alternations in overlapping quintuplets by the number of possible alternations (total number of arm entries -4 ) and multiplying the quotient by 100 (Ragozzino et al. 1998).

\section{Immunohistochemical staining of c-Fos and RLN3 in the NI}

Seven days after the SAT analysis, aCSF-infused rats were further divided into three groups: naïve, handled, and SAT-run $(n=3$ / group). The handled group were carried into the SAT room, picked up, and placed back into their home cage for $1 \mathrm{~h}$, the SAT-run group were placed back into the closed plus-maze for $10 \mathrm{~min}$ and then placed back into their home cage for $1 \mathrm{~h}$, and the naïve group was left undisturbed. Rats were deeply anesthetized by isoflurane inhalation and transcardially perfused with $300 \mathrm{~mL}$ of ice-cold PBS followed by $500 \mathrm{~mL}$ of ice-cold $4 \%$ paraformaldehyde in PBS. Rats were then decapitated, and the brains were dissected and postfixed for a further $1 \mathrm{~h}$ in the same fixative. Brains were transferred to $30 \%$ sucrose in PBS for $\sim 48 \mathrm{~h}$ at $4^{\circ} \mathrm{C}$. Series of coronal sections $(40 \mu \mathrm{m})$ through the MS (all groups) and the NI (aCSF-infused group) were cut on a cryostat at $-16^{\circ} \mathrm{C}$ (Cryocut 1800; Leica Microsystems) and collected into PBS immediately before immunohistochemical processing. Sections through the MS from each rat were slide-mounted and stained with thionin to verify cannula placement.

For c-Fos quantification, free-floating sections were incubated in $1 \% \mathrm{H}_{2} \mathrm{O}_{2}$ and $50 \%$ methanol in $0.05 \mathrm{M}$ Tris-buffered saline containing $0.2 \%(\mathrm{v} / \mathrm{v})$ Triton X-100 (TBX) for 30 min with gentle agitation. All washes were made with TBX. Sections were then washed three times for $10 \mathrm{~min}$ each and incubated in blocking buffer $[10 \%(\mathrm{v} / \mathrm{v})$ NGS and $2 \%$ bovine serum albumin (BSA) in TBX] for $1 \mathrm{~h}$ with agitation at room temperature. Sections were then incubated in TBX containing 1:5000 dilution of rabbit antic-Fos IgG (PC38; Calbiochem), 2\% NGS, and 2\% BSA overnight at $4^{\circ} \mathrm{C}$. Sections were washed three times for $10 \mathrm{~min}$ each and then incubated in a 1:500 dilution of secondary biotinylated goat antirabbit IgG (Vector Laboratories) with gentle agitation for $1 \mathrm{~h}$ at room temperature, followed by three 10 -min washes. Sections were incubated in a 1:100 dilution of avidin-biotin complex (VectaStain Elite; Vector Laboratories) in TBX for a further $1 \mathrm{~h}$ at room temperature, followed by three 10-min washes. Immunostaining was visualized using standard peroxidase-chromogen re-

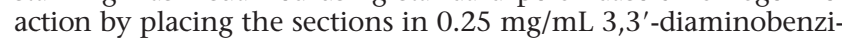
dine (DAB; Sigma-Aldrich) in $0.05 \mathrm{M}$ Tris- $\mathrm{HCl}$ (pH 8.0) containing $0.1 \%$ ammonium nickel sulfate, followed by addition of $0.003 \%$ $\mathrm{H}_{2} \mathrm{O}_{2}$ for 3-5 min.

To quantify percentages of RLN3 and c-Fos double-immunolabeling, sections were incubated in blocking buffer $[10 \%(\mathrm{v} / \mathrm{v})$ NGS and 2\% BSA in TBX] for $1 \mathrm{~h}$ with agitation at room temperature. Sections were then incubated in TBX containing a 1:2500 dilution of rabbit anti-c-Fos IgG (PC38; Calbiochem), 2\% NGS, and $2 \% \mathrm{BSA}$ overnight at $4^{\circ} \mathrm{C}$. Sections were washed three times for 10 min each and then incubated in a 1:250 dilution of secondary biotinylated goat anti-rabbit IgG conjugated to Cy2 (Jackson ImmunoResearch Laboratories Inc.) with gentle agitation for $1 \mathrm{~h}$ at room temperature, followed by four 10-min washes. Sections were then incubated in a 1:1000 dilution of rabbit polyclonal RLN3 antiserum (AS-R3 ${ }_{85-101}$ ) in TBX containing $2 \%$ NGS and $2 \%$ BSA overnight at $4^{\circ} \mathrm{C}$ (Ma et al. 2007). Sections were washed three times for $10 \mathrm{~min}$ each and then incubated in a 1:250 dilution of secondary biotinylated goat antirabbit IgG conjugated to Alexa594 (Invitrogen Corporation) with gentle agitation for $1 \mathrm{~h}$ at room temperature, followed by three 10-min washes. Cross-reactivity was minimized by extensive washing between primary antibodies and could be differentiated by the fact that c-Fos was localized in the nucleus, whereas RLN3 was localized in the cytoplasm of neurons (Ma et al. 2007). Sections were mounted onto gelatin-chrom alum-coated glass microscope slides and coverslipped with Fluoromount mounting medium (Sigma-Aldrich).

\section{Quantification of c-Fos immunoreactivity in the nucleus incertus}

Sections were photographed under brightfield illumination on an Olympus IX70 microscope (Olympus Imaging) equipped with SPOT real-time digital camera with Image-pro 4.5 software (Diagnostics Instruments). The majority of the NI was photographed at $10 \times$ magnification (Fig. 6A,B). Immunoreactivity in one field-of-view from three equivalent sections through rostral, mid, and caudal NI from each rat was quantified using Scion Image 1.63 (National Institutes of Health, Bethesda, MD, USA) and represented as an average number of c-Fos-positive nuclei per micrometer squared. One-Way ANOVA was used to calculate statistical differences between groups.

For RLN3 and c-Fos double-immunofluorescence, sections were analyzed using a Leica DM LB2 microscope (Leica Microsystems Pty. Ltd.) equipped with an Optronics Camera. Samples were imaged sequentially to collect light emitted as red or green fluorescence using $10 \times$ magnification. Images were adjusted for brightness and contrast and merged using ImageJ (National Institutes of Health). Immunoreactivity of one field-of-view from three equivalent sections through rostral, mid, and caudal NI from each rat was used to manually count the numbers of RLN3 only; c-Fos and RLN3; and c-Fos only. One-way ANOVA was used to calculate statistical differences between groups. 


\section{Histological studies of the NI}

Adult Sprague-Dawley rats (250-350 g; $n=5)$ were obtained from Harlan Olac Ltd (Bicester, UK). All surgical procedures were performed according to the animal care guidelines of the European Council (86/609/EEC) and approved by the Ethics Committee of the University of Valencia. Rats were housed in a thermoregulated environment in a 12-h light/dark cycle, with food and water ad libitum.

\section{Surgical microinjection of dual fluorescent tracers}

Rats were anesthetized with a mixture of ketamine $50-60 \mathrm{mg} / \mathrm{kg}$, i.p. (Imalgen, $0.05 \mathrm{~g} / \mathrm{mL}$; Rhône Mérieux) and xylazine $10 \mathrm{mg} / \mathrm{kg}$, i.p. (Xilagesic, $20 \mathrm{mg} / \mathrm{mL}$; Lab Calier) and placed into a stereotaxic frame (Kopf Instruments). Trephine holes were drilled in the skull based on stereotaxic coordinates according to the atlas of Paxinos and Watson (1986).

Anterograde tracer, dextran tetramethylrhodamine, and biotin (mR, Invitrogen-Molecular Probes) diluted $15 \%$ in $0.1 \mathrm{M} \mathrm{PB}$ $(\mathrm{pH}$ 7.4) were iontophoretically delivered through a glass micropipette with an inner tip diameter of 20-25 $\mu \mathrm{m}$, made in a pipette puller (Narishige) into the NI (coordinates from bregma: $9.5 \mathrm{~mm}$ posterior, $0.0 \mathrm{~mm}$ lateral, $7.6 \mathrm{~mm}$ ventral) using a current of +1.2 $\mu \mathrm{A}$ ( $2 \mathrm{sec}$ on/2 sec off) over $10 \mathrm{~min}$. Retrograde tracer, hydroxystilbamidine methanesulfonate (FG, Invitrogen-Molecular Probes), diluted 5\% in acetate buffer ( $\mathrm{pH} 4.0$ ) was injected into the hippocampus (coordinates from bregma: $5.2 \mathrm{~mm}$ posterior, $-5.0 \mathrm{~mm}$ lateral, $5.0 \mathrm{~mm}$ ventral) using a $1-\mu \mathrm{L}$ Hamilton syringe to deliver $0.2-0.5 \mu \mathrm{L}$. Reflux was minimized by leaving the pipette and syringe in place for a further $10 \mathrm{~min}$ after cessation of injections. Rats were then sutured and allowed to recover for $7 \mathrm{~d}$.

\section{Fixation and tissue preparation}

Rats were deeply anesthetized with sodium pentobarbital (100 $\mathrm{mg} / \mathrm{kg}, 20 \%$; Dolethal, Vetoquinol) and transcardially perfused with $500 \mathrm{~mL}$ of $0.1 \%$ heparinzed saline $(0.9 \%, \mathrm{pH} 7.0)$ followed by $500 \mathrm{~mL}$ of fixative composed of $4 \%$ paraformaldehyde (SigmaAldrich), $0.2 \%$ glutaraldehyde (Sigma-Aldrich), and 15\% saturated picric acid (Sigma-Aldrich) in 0.1 M PB (pH 7.4). The brain was post-fixed in the head for $1 \mathrm{~h}$ and then removed from the skull and stored in $0.1 \mathrm{M} \mathrm{PB}(\mathrm{pH}$ 7.4) containing $0.05 \%$ sodium azide (Sigma-Aldrich). Coronal sections were obtained with a Vibratome (Leica VT-1000 M; Leica Microsystems) and collected in the same solution before processing.

\section{Immunohistochemistry following FG and $\mathrm{mR}$ injections}

Brain sections with FG and $\mathrm{mR}$ injections were further processed for RLN3-LI as described (Ma et al. 2007). For fluorescence microscopy, tissues were incubated in a 1:50 dilution of secondary biotinylated anti-rabbit IgG conjugated to FITC (Vector Laboratories) with gentle agitation for $3 \mathrm{~h}$ at room temperature, followed by three 10-min washes. Sections were mounted onto gelatin-chrom alum-coated glass microscope slides and coverslipped using Dako FluoroMount (Dako).

\section{Dual immunohistochemical labeling of RLN3 and calcium-binding proteins}

Sections were processed as described for c-Fos immunohistochemistry. Immunostaining for RLN3 was visualized using standard peroxidase-chromagen reaction by placing sections in Tris/HCl ( $\mathrm{pH}$ 8.0) containing $0.025 \% \mathrm{DAB}$ enhanced with $\mathrm{NiNH}_{4} \mathrm{SO}_{4}$ and activated with $0.04 \% \mathrm{H}_{2} \mathrm{O}_{2}$. After extensive washing - six times for 10 min each-in TBS, sections were incubated in blocking buffer for $1 \mathrm{~h}$ at room temperature and placed in solutions of monoclonal antibodies against calcium-binding proteins parvalbumin (1:5000; Sigma-Aldrich), calbindin (1:5000; Sigma-Aldrich), or calretinin (1:5000; Sigma-Aldrich) containing 2\% BSA, 2\% NGS, and $0.2 \%$ Triton X-100 (pH 7.4) for $\sim 18 \mathrm{~h}$ with gently shaking at $4^{\circ} \mathrm{C}$, followed by three 10-min washes. Sections were visualized using standard peroxidase-chromagen reaction without nickel enhancement. After three 10-min washes, sections were mounted onto gelatin-chrom alum-coated glass microscope slides and left to dry overnight, dehydrated, and cleared through a series of ethanol and xylene and coverslipped using DPX mounting media (SigmaAldrich).

\section{Ultrastructural analysis of NI presynaptic terminals in the MS using electron microscopy}

Some sections with $\mathrm{mR}$ injections were processed for electron microscopy. To increase antibody penetration, sections were cryoprotected by immersing in a solution of 10\% glycerol, $25 \%$ sucrose in $0.05 \mathrm{M} \mathrm{PB}$ at $\mathrm{pH} 7.4$ for $1 \mathrm{~h}$. Sections passed through three cycles of freeze-thawing by mounting each on aluminum foil and contacting it to the surface of liquid nitrogen for 2-3 sec. Sections were rinsed in $0.1 \mathrm{M} \mathrm{PB}$ and incubated overnight in a 1:100 dilution of avidin-biotin complex (VectaStain Elite; Vector Laboratories). The following day, sections were incubated in $0.015 \% \mathrm{DAB}, 0.004 \% \mathrm{H}_{2} \mathrm{O}_{2}$ in $0.1 \mathrm{M}$ PB for $20 \mathrm{~min}$. Sections were rinsed four times for $10 \mathrm{~min}$ each in $0.1 \mathrm{M} \mathrm{PB}$. Osmication was performed by immersing sections in $1 \%$ osmium tetroxide (SigmaAldrich), 7\% glucose in $0.1 \mathrm{M} \mathrm{PB}$ for $1 \mathrm{~h}$. Sections were rinsed in $0.1 \mathrm{M}$ PB three times for $10 \mathrm{~min}$ each. Inclusion was performed by passing sections through a graded series of ethanol (two times for 3 min each at 30\%, two times for $10 \mathrm{~min}$ each at $50 \%$, two times for $10 \mathrm{~min}$ each at 70\%, 2\% uranyl acetate in $70 \%$ ethanol for $75 \mathrm{~min}$, two times for $3 \mathrm{~min}$ each at $70 \%$, two times for $10 \mathrm{~min}$ each at $96 \%$, three times for $10 \mathrm{~min}$ each at 100\%). Sections were immersed in propylene oxide twice for $8 \mathrm{~min}$ and embedded in Durcupan resin (Sigma-Aldrich) overnight at room temperature. The following day, sections were sandwiched between two acetate sheets embedded in the same resin for $72 \mathrm{~h}$ at $60^{\circ} \mathrm{C}$. Semi-thin sections were obtained with an Ultracut ultramicrotome, and selected regions were again sectioned into ultra-thin sections that were studied with a Jeol JEM-1010 electron microscope (Jeol Ltd.). Images were captured with a MegaViewIII digital camera and the AnalySIS software.

\section{Microscopy, image acquisition, and processing}

Verification of the injection sites was performed by light microscopy using a Nikon Eclipse E600 (Nikon), equipped with the appropriate fluorescence filters: for FG UV-2A (EX 330-380, DM 400, BA 420) and for mR G-2A (EX 510-560, DM 575, BA 590). Images were acquired in grayscale using a Nikon DMX-2000 camera and sent to a PC with ACT-1 acquisition software (Nikon) to convert to false color. The images were exported to Adobe Photoshop CS2, which was used to compensate for levels of brightness and contrast for analysis to generate images illustrating the qualitative distribution of immunoreactivity.

\section{Acknowledgments}

This research was supported by grants from the National Health and Medical Research Council (NHMRC) of Australia (\#520299 to S.M., \#277609 and \#509246 to A.L.G., and \#509048 to J.D.W.), from the ISCIII-FIS of the Ministry of Health (PI061816 FEOB), and a collaborative research agreement between the Howard Florey Institute and Johnson \& Johnson Pharmaceutical Research \& Development, LLC. S.M. is a recipient of an NHMRC Australian Biomedical Fellowship, and J.D.W. and A.L.G. are NHMRC (Australia) Research Fellows. We thank María Teresa Mínguez (SCSIEUV) for her technical assistance in preparing EM samples. We also thank the Howard Florey Biomedical Foundation (USA), Ian Potter Foundation of Australia, ANZ Trustees Medical Research and Technology, and the GW Vowell Foundation for their support.

\section{References}

Asaka Y, Mauldin KN, Griffin AL, Seager MA, Shurell E, Berry SD. 2005. Nonpharmacological amelioration of age-related learning deficits: The impact of hippocampal theta-triggered training. Proc Natl Acad Sci 102: 13284-13288.

Banerjee A, Shen P-J, Gundlach AL. 2006. Relaxin-3 neurons in nucleus incertus of the rat: Effect on activity of psychological stress and the light-dark cycle. Poster session at FENS Forum of Neuroscience Abstracts, 
Vol. 3, A117.2, Vienna, Austria. http://fens2006.neurosciences.asso.fr/ abstracts/R4/A117_2.html.

Banerjee A, Shen P-J, Ma S, Bathgate RAD, Gundlach AL. 2009. Swim stress excitation of nucleus incertus and rapid induction of relaxin-3 expression via $\mathrm{CRF}_{1}$ activation. Neuropharmacology (in press). doi: 10.1016/j.neuropharm.2009.06.019.

Bathgate RAD, Samuel CS, Burazin TCD, Layfield S, Claasz AA, Reytomas IG, Dawson NF, Zhao C, Bond C, Summers RJ, et al. 2002. Human relaxin gene 3 (H3) and the equivalent mouse relaxin (M3) gene. Novel members of the relaxin peptide family. J Biol Chem 277: 1148-1157.

Bathgate RAD, Hsueh AJ, Sherwood OD. 2006. Physiology and molecular biology of the relaxin peptide family. In Knobil and Neill's physiology of reproduction, 3rd ed. (eds. P Wassarman and JD Neill), pp. 701-790. Elsevier, New York.

Bittencourt JC, Sawchenko PE. 2000. Do centrally administered neuropeptides access cognate receptors? An analysis in the central corticotropin-releasing factor system. J Neurosci 20: 1142-1156.

Burazin TCD, Bathgate RAD, Macris M, Layfield S, Gundlach AL, Tregear GW. 2002. Restricted, but abundant, expression of the novel rat gene-3 (R3) relaxin in the dorsal tegmental region of brain. J Neurochem 82: 1553-1557.

Cisse RS, Krebs-Kraft DL, Parent MB. 2008. Septal infusions of the hyperpolarization-activated cyclic nucleotide-gated channel (HCNchannel) blocker ZD7288 impair spontaneous alternation but not inhibitory avoidance. Behav Neurosci 122: 549-556.

Cummins TD, Finnigan S. 2007. Theta power is reduced in healthy cognitive aging. Int J Psychophysiol 66: 10-17.

Cummins TD, Broughton M, Finnigan S. 2008. Theta oscillations are affected by amnestic mild cognitive impairment and cognitive load. Int J Psychophysiol 70: 75-81.

Givens BS, Olton DS, Crawley JN. 1992. Galanin in the medial septal area impairs working memory. Brain Res 582: 71-77.

Goto M, Swanson LW, Canteras NS. 2001. Connections of the nucleus incertus. J Comp Neurol 438: 86-122.

Gulyas AI, Hajos N, Katona I, Freund TF. 2003. Interneurons are the local targets of hippocampal inhibitory cells which project to the medial septum. Eur J Neurosci 17: 1861-1872.

Hangya B, Borhegyi Z, Szilagyi N, Freund TF, Varga V. 2009. GABAergic neurons of the medial septum lead the hippocampal network during theta activity. J Neurosci 29: 8094-8102.

Hasselmo ME. 2005. What is the function of hippocampal theta rhythm? Linking behavioral data to phasic properties of field potential and unit recording data. Hippocampus 15: 936-949.

Haugaard-Jonsson LM, Hossain MA, Daly NL, Bathgate RAD, Wade JD, Craik DJ, Rosengren KJ. 2008. Structure of the R3/I5 chimeric relaxin peptide, a selective GPCR135 and GPCR142 agonist. J Biol Chem 283: 23811-23818.

Henderson Z, Fiddler G, Saha S, Boros A, Halasy K. 2004. A parvalbumin containing, axosomatic synaptic network in the rat medial septum: Relevance to rhythmogenesis. Eur J Neurosci 19: 2753-2768.

Hida T, Takahashi E, Shikata K, Hirohashi T, Sawai T, Seiki T, Tanaka H, Kawai T, Ito O, Arai T, et al. 2006. Chronic intracerebroventricular administration of relaxin-3 increases body weight in rats. J Recept Signal Transduct Res 26: 147-158.

Hossain MA, Rosengren KJ, Haugaard-Jonsson LM, Zhang S, Layfield S, Ferraro T, Daly NL, Tregear GW, Wade JD, Bathgate RAD. 2008. The A-chain of human relaxin family peptides has distinct roles in the binding and activation of the different relaxin family peptide receptors. J Biol Chem 283: 17287-17297.

Hossain MA, Bathgate RAD, Rosengren KJ, Shabanpoor F, Zhang S, Lin F, Tregear GW, Wade JD. 2009. The structural and functional role of the B-chain C-terminal arginine in the relaxin-3 peptide antagonist, R3(B $\Delta 23-27) R / I 5$. Chem Biol Drug Des 73: 46-52.

Hsu SY. 2003. New insights into the evolution of the relaxin-LGR signaling system. Trends Endocrinol Metab 14: 303-309.

Hsu SY, Semyonov J, Park JI, Chang CL. 2005. Evolution of the signaling system in relaxin-family peptides. Ann N Y Acad Sci 1041: 520-529.

Kirk IJ, Mackay JC. 2003. The role of theta-range oscillations in synchronising and integrating activity in distributed mnemonic networks. Cortex 39: 993-1008.

Kiss J, Patel AJ, Freund TF. 1990. Distribution of septohippocampal neurons containing parvalbumin or choline acetyltransferase in the rat brain. J Comp Neurol 298: 362-372.

Kiss J, Magloczky Z, Somogyi J, Freund TF. 1997. Distribution of calretinincontaining neurons relative to other neurochemically identified cell types in the medial septum of the rat. Neuroscience 78: 399-410.

Klimesch W. 1999. EEG alpha and theta oscillations reflect cognitive and memory performance: A review and analysis. Brain Res Brain Res Rev 29: 169-195.

Kocsis B. 2006. The effect of descending theta rhythmic input from the septohippocampal system on firing in the supramammillary nucleus. Brain Res 1086: 92-97.
Kuei C, Sutton S, Bonaventure P, Pudiak C, Shelton J, Zhu J, Nepomuceno D, Wu J, Chen J, Kamme F, et al. 2007. R3(B $\Delta 23-27) R / I 5$ chimeric peptide, a selective antagonist for GPCR135 and GPCR142 over relaxin receptor LGR7: In vitro and in vivo characterization. J Biol Chem 282: 2542525435 .

Lalonde R. 2002. The neurobiological basis of spontaneous alternation. Neurosci Biobehav Rev 26: 91-104.

Liu C, Eriste E, Sutton S, Chen J, Roland B, Kuei C, Farmer N, Jornvall H, Sillard R, Lovenberg TW. 2003. Identification of relaxin-3/INSL7 as an endogenous ligand for the orphan G-protein coupled receptor GPCR135. J Biol Chem 278: 50754-50764.

Liu C, Chen J, Kuei C, Sutton SW, Nepomuceno D, Bonaventure P, Lovenberg TW. 2005. Relaxin-3/insulin-like peptide 5 chimeric peptide, a selective ligand for G protein-coupled receptor (GPCR)135 and GPCR142 over leucine-rich repeat-containing $\mathrm{G}$ protein-coupled receptor 7. Mol Pharmacol 67: 231-240.

Ma S, Gundlach AL. 2007. Relaxin-family peptide and receptor systems in brain: Insights from recent anatomical and functional studies. Adv Exp Med Biol 612: 119-137.

Ma S, Roozendaal B, Burazin TCD, Tregear GW, McGaugh JL, Gundlach AL. 2005. Relaxin receptor activation in the basolateral amygdala impairs memory consolidation. Eur J Neurosci 22: 2117-2122.

Ma S, Bonaventure P, Ferraro T, Shen P-J, Burazin TCD, Bathgate RAD, Liu C, Tregear GW, Sutton SW, Gundlach AL. 2007. Relaxin-3 in GABA projection neurons of nucleus incertus suggests widespread influence on forebrain circuits via G-protein-coupled receptor-135 in the rat. Neuroscience 144: 165-190.

Ma S, Sang Q, Lanciego JL, Gundlach AL. 2009. Localization of relaxin-3 in brain of Macaca fascicularis-identification of nucleus incertus in primate. J Comp Neurol doi: 10.1002/cne.22197.

Matsumoto M, Kamohara M, Sugimoto T, Hidaka K, Takasaki J, Saito T, Okada M, Yamaguchi T, Furuichi K. 2000. The novel G-protein coupled receptor SALPR shares sequence similarity with somatostatin and angiotensin receptors. Gene 248: 183-189.

McGowan BM, Stanley SA, Smith KL, Minnion JS, Donovan J, Thompson EL, Patterson M, Connolly MM, Abbott CR, Small CJ, et al. 2006. Effects of acute and chronic relaxin-3 on food intake and energy expenditure in rats. Regul Pept 136: 72-77.

McNaughton N, Feldon J. 1980. Spontaneous alternation of body turns and place: Differential effects of amylobarbitone, scopolamine and septal lesions. Psychopharmacology 68: 201-206.

McNaughton N, Gray JA. 2000. Anxiolytic action on the behavioural inhibition system implies multiple types of arousal contribute to anxiety. J Affect Disord 61: 161-176.

Nuñez A, de Andres I, Garcia-Austt E. 1991. Relationships of nucleus reticularis pontis oralis neuronal discharge with sensory and carbachol evoked hippocampal theta rhythm. Exp Brain Res 87: 303-308.

Nuñez A, Cervera-Ferri A, Olucha-Bordonau F, Ruiz-Torner A, Teruel V. 2006. Nucleus incertus contribution to hippocampal theta rhythm generation. Eur J Neurosci 23: 2731-2738.

Olucha-Bordonau FE, Teruel V, Barcia-Gonzalez J, Ruiz-Torner A, ValverdeNavarro AA, Martinez-Soriano F. 2003. Cytoarchitecture and efferent projections of the nucleus incertus of the rat. J Comp Neurol 464: 62-97.

Paxinos G, Watson C. 1986. The rat brain in stereotaxic coordinates. Academic Press, New York.

Peters A, Palay SL. 1996. The morphology of synapses. I Neurocytol 25: 687-700.

Ragozzino ME, Pal SN, Unick K, Stefani MR, Gold PE. 1998. Modulation of hippocampal acetylcholine release and spontaneous alternation scores by intrahippocampal glucose injections. J Neurosci 18: 1595-1601.

Simon AP, Poindessous-Jazat F, Dutar P, Epelbaum J, Bassant MH. 2006 Firing properties of anatomically identified neurons in the medial septum of anesthetized and unanesthetized restrained rats. J Neurosci 26: 9038-9046.

Smith HR, Pang KC. 2005. Orexin-saporin lesions of the medial septum impair spatial memory. Neuroscience 132: 261-271.

Stefani MR, Gold PE. 1998. Intra-septal injections of glucose and glibenclamide attenuate galanin-induced spontaneous alternation performance deficits in the rat. Brain Res 813: 50-56.

Sutton SW, Bonaventure P, Kuei C, Roland B, Chen J, Nepomuceno D, Lovenberg TW, Liu C. 2004. Distribution of G-protein-coupled receptor (GPCR) 135 binding sites and receptor mRNA in the rat brain suggests a role for relaxin-3 in neuroendocrine and sensory processing. Neuroendocrinology 80: 298-307.

Tanaka M, Iijima N, Miyamoto Y, Fukusumi S, Itoh Y, Ozawa H, Ibata Y. 2005. Neurons expressing relaxin 3/INSL 7 in the nucleus incertus respond to stress. Eur J Neurosci 21: 1659-1670.

Teruel-Marti V, Cervera-Ferri A, Nuñez A, Valverde-Navarro AA, OluchaBordonau FE, Ruiz-Torner A. 2008. Anatomical evidence for a pontoseptal pathway via the nucleus incertus in the rat. Brain Res 1218: 87-96.

van der Westhuizen ET, Werry TD, Sexton PM, Summers RJ. 2007. The relaxin family peptide receptor 3 activates extracellular signal-regulated 
kinase 1/2 through a protein kinase C-dependent mechanism. Mol Pharmacol 71: 1618-1629.

Vertes RP. 1984. Brainstem control of the events of REM sleep. Prog Neurobiol 22: 241-288.

Vertes RP. 2005. Hippocampal theta rhythm: A tag for short-term memory. Hippocampus 15: 923-935.

Vertes RP, Fass B. 1988. Projections between the interpeduncular nucleus and basal forebrain in the rat as demonstrated by the anterograde and retrograde transport of WGA-HRP. Exp Brain Res 73: 23-31.

Vertes RP, Kocsis B. 1997. Brainstem-diencephalo-septohippocampal systems controlling the theta rhythm of the hippocampus. Neuroscience 81: 893-926.

Vertes RP, Martin GF. 1988. Autoradiographic analysis of ascending projections from the pontine and mesencephalic reticular formation and the median raphe nucleus in the rat. J Comp Neurol 275: 511-541.
Vertes RP, Colom LV, Fortin WJ, Bland BH. 1993. Brainstem sites for the carbachol elicitation of the hippocampal theta rhythm in the rat. Exp Brain Res 96: 419-429.

Wang XJ. 2002. Pacemaker neurons for the theta rhythm and their synchronization in the septohippocampal reciprocal loop. $J$ Neurophysiol 87: 889-900.

Wilkinson TN, Speed TP, Tregear GW, Bathgate RAD. 2005. Evolution of the relaxin-like peptide family. BMC Evol Biol 5: 14. doi: 10.1186/14712148-5-14.

Wu M, Shanabrough M, Leranth C, Alreja M. 2000. Cholinergic excitation of septohippocampal GABA but not cholinergic neurons: Implications for learning and memory. J Neurosci 20: 3900-3908.

Received March 21, 2009; accepted in revised form August 18, 2009. 


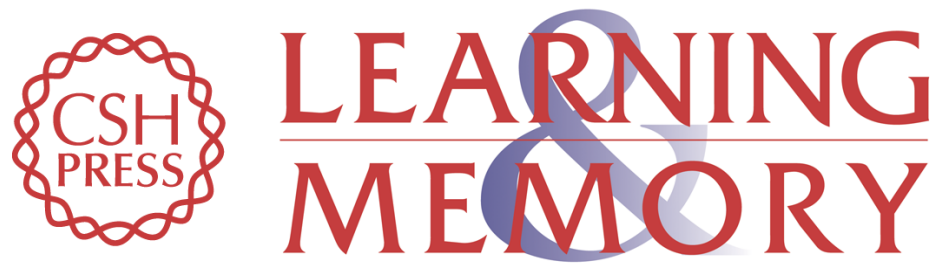

\section{Modulation of hippocampal theta oscillations and spatial memory by relaxin-3 neurons of the nucleus incertus}

Sherie Ma, Francisco E. Olucha-Bordonau, M. Akhter Hossain, et al.

Learn. Mem. 2009, 16:

Access the most recent version at doi:10.1101//m.1438109

Supplemental http://learnmem.cshlp.org/content/suppl/2009/11/24/16.11.730.DC1
Material

References This article cites 58 articles, 13 of which can be accessed free at: http://learnmem.cshlp.org/content/16/11/730.full.html\#ref-list-1

License

Email Alerting Receive free email alerts when new articles cite this article - sign up in the box at the Service top right corner of the article or click here. 